Article

\title{
Assessment of Rainfall Distributions and Characteristics in Coastal Provinces of the Vietnamese Mekong Delta under Climate Change and ENSO Processes
}

\author{
Vinh Hoa Dang ${ }^{1,2}{ }^{(}$, Dung Duc Tran ${ }^{3,4, *}$, Dao Dinh Cham ${ }^{2,5}$, Phan Thi Thanh Hang ${ }^{2,5}(\mathbb{C}$, \\ Hung Thanh Nguyen ${ }^{1}$, Hieu Van Truong ${ }^{1}$, Phuong Ha Tran ${ }^{1,6}$, Man Ba Duong ${ }^{1}$, \\ Ninh Trung Nguyen ${ }^{1}$, Kiem Van Le ${ }^{7}$, Thuc Bich Thi Pham ${ }^{8}$ and Au Hai Nguyen ${ }^{9}$ \\ 1 HCMC Institute of Resources Geography, Vietnam Academy of Science and Technology, \\ Ho Chi Minh City 700000, Vietnam; dhvinh@hcmig.vast.vn (V.H.D.); nthung@vast.vn (H.T.N.); \\ truongvanhieutvmt@yahoo.com (H.V.T.); thphuong@hcmig.vast.vn (P.H.T.); \\ dbman@hcmig.vast.vn (M.B.D.); trungninh.dhtl@gmail.com (N.T.N.) \\ 2 Graduate University of Science and Technology, Vietnam Academy of Science and Technology, Hanoi 100000, \\ Vietnam; ddcham@ig.vast.vn (D.D.C.); hangphanvn@yahoo.com (P.T.T.H.) \\ 3 Center of Water Management and Climate Change, Institute for Environment and Resources, \\ Vietnam National University, Ho Chi Minh City 700000, Vietnam \\ 4 Institute of Research and Development, Duy Tan University, Danang 550000, Vietnam \\ 5 Institute of Geography, Vietnam Academy of Science and Technology, Hanoi 100000, Vietnam \\ 6 University of Social Sciences and Humanities, Vietnam National University, \\ Ho Chi Minh City 700000, Vietnam \\ 7 Southern Institute for Water Resources Research, Ho Chi Minh City 700000, Vietnam; kiemsiwrr@gmail.com \\ 8 Institute of Applied Mechanics and Informatics, Vietnam Academy of Science and Technology, \\ Ho Chi Minh City 700000, Vietnam; ptbthuc@iami.vast.vn \\ 9 Institute for Environment and Resources, Vietnam National University, Ho Chi Minh City 700000, Vietnam; \\ haiauvtn@gmail.com \\ * Correspondence: dungtranducvn@yahoo.com
}

Received: 20 April 2020; Accepted: 26 May 2020; Published: 29 May 2020 updates

\begin{abstract}
Rainwater is considered a promising alternative water source for coastal areas where freshwater resources are increasingly under pressure. This study evaluates rain regime characteristics that influence the ability to exploit rainwater in the coastal provinces of the Vietnamese Mekong Delta (VMD). In particular, it considers the impact of climate change and El Niño-Southern Oscillation (ENSO) processes. We analyzed rainfall data from 102 monitoring stations across the VMD from 1989 to 2017. Using statistical methods, we explored (1) characteristics of the rainy season, including the dates of onset and cessation and season length; (2) average rainfall volumes; and (3) the maximum number of consecutive nonrainy days during the rainy season and over the year. We also analyzed changes in these characteristics over time, in parallel with ENSO processes and climate change. Trend lines were determined using nonparametric methods, utilizing Sen's slope estimation and the Mann-Kendall test. Results showed a tendency for the rainy season to start earlier and end later in the western coastal zone of the study area, with season length gradually decreasing towards the East Sea and inland. The shortest rainy season was found in the estuary zone (in the northeast of the VMD). Rainfall was abundant on the west coast, again diminishing gradually towards the East Sea and inland. Rain was also quite plentiful during four dry season observation months in the study area, but it lacked the predictability needed for effective exploitation. The number of consecutive days without rain averaged 96 annually, with a difference of 29 days between the largest and smallest observations. The difference between the provinces with the longest and shortest periods without rain averaged 41 days. Although the impact of climate change on the rain regime is complex, we can say
\end{abstract}


that the rainy season now tends to start earlier, end later, and be lengthier, though without exhibiting clear trends. ENSO processes significantly impacted rainfall regime characteristics, especially the dates of onset and cessation, and season length.

Keywords: rainfall; groundwater; Mekong; ENSO; climate change

\section{Introduction}

Rain is a major component of the global climate system, playing a central role in connecting processes on the ground, in the atmosphere, and in the oceans [1]. Rain is also an essential component of the global water balance and energy balance. However, it is also among the components most greatly affected by climate change [2]. Changes in the distribution and characteristics of rainfall linked to the effects of climate change have been demonstrated as underlying recent serious hydrological events, such as floods, droughts, freshwater scarcity, water pollution and groundwater depletion $[2,3]$.

Coastal areas are home to diverse and abundant ecosystems [4]. They are also among the zones most vulnerable to natural fluctuations, such as those associated with climate change and the El Niño-Southern Oscillation (ENSO) cycle, alongside human influences such as construction and residential activities [5]. Yet, more than half of the world's major cities are located within $50 \mathrm{~km}$ of the coast, and the population density here is 2.6 times higher than inland [6]. In terms of economic activity, coastal zones are among the most productive areas for freshwater and saltwater aquaculture, agricultural production, and industry. As a result of this intensity of activity, coastal areas often have difficulty accessing sufficient freshwater and allocating freshwater among the many competing uses. Moreover, the freshwater that flows to coastal areas from upstream may be affected by saltwater intrusion from the sea, which is another factor that makes it difficult for coastal people to actively exploit local freshwater resources, especially for production and drinking [6]. Overexploitation of groundwater to meet livelihood and development needs can lead to resource degradation. Around the globe, this is evident in indirect and direct pollution of soils and groundwater, the decline of aquifers, and severe subsidence, with these problems often most apparent in coastal areas [7-9].

This study focused on the Vietnamese Mekong Delta (VMD), which is a typical example of the abovementioned problems $[7,9,10]$. A series of hydropower dams has been built upstream in the VMD, changing streamflow and undermining functions downstream in the delta. Under the impact of climate change, which has led to increased saltwater intrusion, the freshwater resources in the VMD coastal zone have come under particular threat and in some cases are exhausted [11]. Agricultural and industrial activities in the study area thus face severely constrained freshwater availability.

Finding alternative water sources so that use of groundwater can be minimized is an urgent task along the VMD coast. Rainwater could offer high potential as an alternative water source. Rain can be harvested directly by water users and is considered a relatively accessible water source [12]. However, rainwater exploitation is limited by several factors, particularly, (1) the variability of the rainy season, especially fluctuation in the dates of onset and cessation of the rainy season and in rainy season length; (2) the long period of the year without rain, which necessitates sufficiently large storage capacities to meet user requirements; and (3) the difficulty of predicting the amounts and frequency of intermittent rainfall during the dry season along the VMD coast.

Several studies have presented the importance of exploring rainfall characteristics and distributions to agricultural production and other purposes, i.e., dates of onset and cessation of the rainy season and season length or volume [13-15]. To our best knowledge, no study has been carried out to investigate spatial and temporal rainfall distributions and characteristics in the coastal area of the VMD, although a few studies have put great efforts to explore the rainfall pattern at larger scales. Gobin et al. [16] explored the heavy rainfall patterns for eight climatic zones of Vietnam using 56 meteorological stations. In his study, the Mekong Delta was founded as the area having the longest rainy season, 
and all zones have been influenced by El Niño and La Niña. In another study, Ono et al. [17] analyzed extreme daily rainfall in the Mekong River Basin using a gridded precipitation dataset of the Asian Precipitation Highly Resolved Observational Data Integration Towards Evaluation of Water Resources (APHRODITE). However, these methods and findings could not be used for determining when and where rainfall could be collected for use. Therefore, our study is conducted.

To help resolve these issues, this study posed three research questions: (1) How has the rainy season in the study area changed over the past decades, particularly regarding the dates of onset and cessation of the rainy season and season length? (2) How much rain falls in the study area? (3) What is the most prolonged rain-free period?

Obtaining answers to these questions will help planners evaluate the potential for rainwater collection and use. For example, understanding the volume of rainwater that falls, particularly the quantities that could potentially fall onto the available clean roof space, is essential to determine whether rainwater could in fact meet user requirements. Knowing how long users may have to go without new rainfall will help in determining how much water storage would be required to meet demands during dry or drought periods.

The study area is strongly affected by climate change and ENSO processes, though the impacts differ over both space and time. Detailed analysis and evaluation are therefore required to arrive at appropriate responses. To that end, the current research investigated the characteristics and distribution of rainfall in the coastal zone of the VMD. Our analyses specifically sought to suggest policy directions for effectively minimizing exploitation of groundwater by maximizing efficient use of rainwater.

\section{Study Area and Objectives}

\subsection{Study Area}

This study concerns the coastal provinces of the VMD, including Tien Giang, Ben Tre, Tra Vinh, Soc Trang, Bac Lieu, Ca Mau, and Kien Giang (Figure 1). Due to the geographical characteristics and distribution of water resources here, we divided the study area into three subregions: the estuaries (Tien Giang, Ben Tre, and Soc Trang), the Ca Mau Peninsula (CMP, including Soc Trang, Bac Lieu, Ca Mau, and Kien Giang), and the Long Xuyen Quadrangle (LXQ, represented by Kien Giang Province in this study).

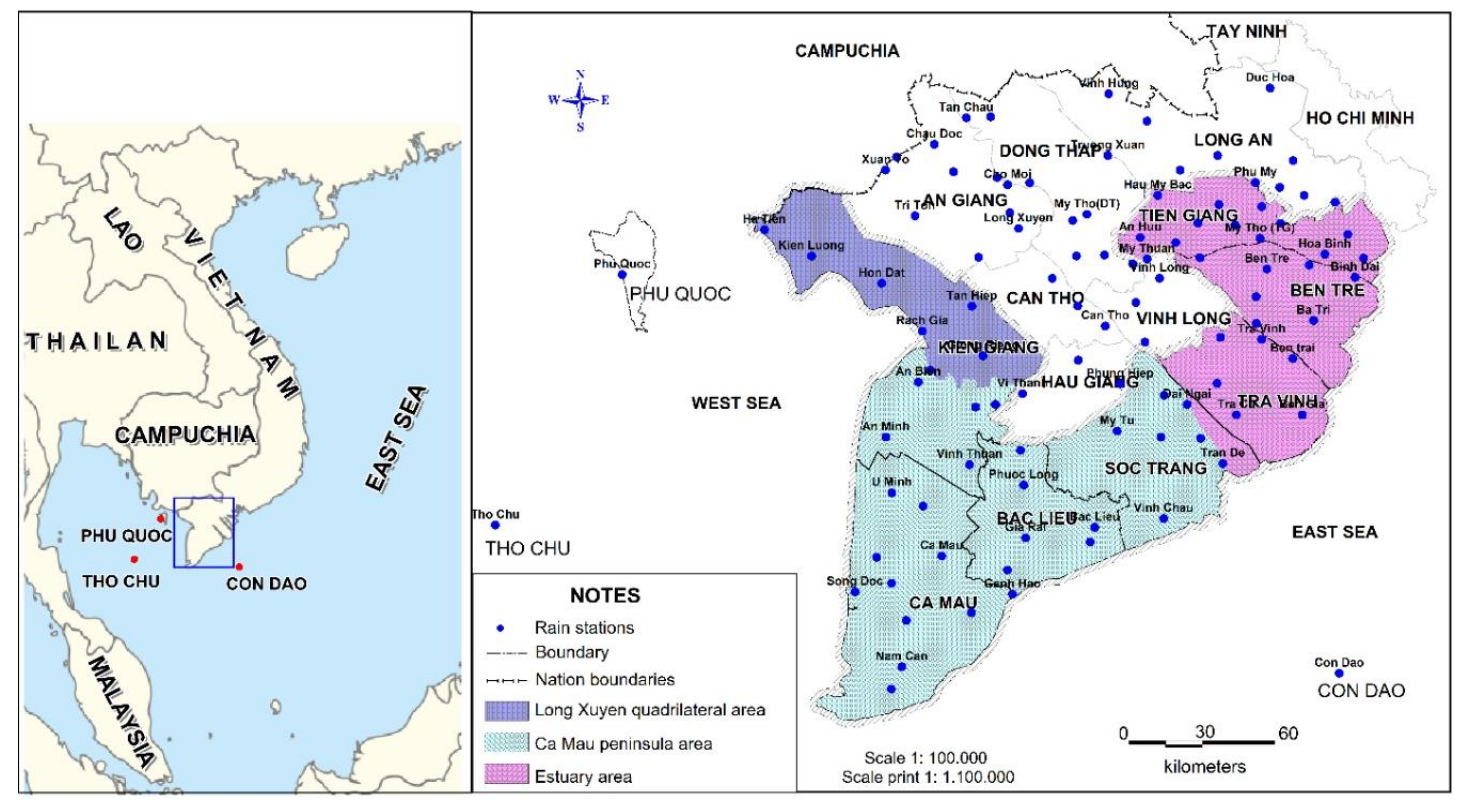

Figure 1. Map (left) showing the study area at Vietnam's southernmost tip and the location of three rain gauges in the East Sea (Phu Quoc, Tho Chu, and Con Dao). Map (right) showing provincial boundaries, the three subregions (the estuaries), Ca Mau Peninsula (CMP), and the Long Xuyen Quadrangle (LXQ), as well as 104 rain gauging locations. 
The rainy season in Southeast Asia, which includes Vietnam and the VMD region, is associated with the southwest monsoon (summer monsoon). The southwest monsoon flows from sea to land, strengthened by the movement of the Inter Tropical Convergence Zone (ITCZ) to the south, and by westward expansion of the subtropical South Pacific High $[1,13,18]$. Because of its origin, the southwest monsoon brings large amounts of rainfall over the VMD. The southwest monsoon is not stable, but always fluctuates in waves. Each period, lasting 5-10 days, is characterized by an onset, maintenance, and weakening phase [18]. Around October, with the formation of a high-pressure area over the Asian continent, the ITCZ moves south and subtropical high pressure decreases and retreats to the east, causing the southwest monsoon to weaken and the northeast monsoon to form and develop [18]. The convergence between the southwest and northeastern monsoon zones influences wind directions in the study area. In the areas most influenced by the ITCZ, monsoon rainfall is quite high. The rainy season in the study area ends when the southwest monsoon system dissipates [19].

The begin and end dates of the rainy season in the VMD are thus associated with the formation, development, and weakening of the monsoon system. However, rainfall remains difficult to predict, due to the complex interactions between many different weather systems. Besides, rainfall is strongly influenced by local conditions $[13,20]$. This means that the begin and end dates of the rainy season may differ from the onset and cessation dates of the southwest monsoon season. In practice, the rainy season often begins later than the southwest monsoon and ends later. However, the start and end dates of the rainy season are not monitored, so no historical data series for it are available. Rather, these tend to be inferred from rainfall data.

\subsection{Research Objectives}

This study focused on three key characteristics of rainfall in the study area. The first, rainy season characteristics, is defined by the date of onset of the rainy season (ORD), the cessation date of the rainy season (CRD), and the length of the rainy season (LRS). An understanding of these characteristics is essential to determine the potential of rainwater harvesting, as these aspects are needed to calculate the water balance for any potential harvesting system as well as for storage capacity planning.

The second characteristic, rainfall volumes, is important to determine the potential of rainwater harvesting to meet user requirements. It is measured as the total volume of rain that falls in a year (VRY), which was available as a time series. However, rainwater harvesting is constrained by lengthy periods without rain. In this regard, out-of-season rains can play an important role in expanding the usability of rainwater harvesting systems. We, therefore, incorporated out-of-season rains into our study as the amount of precipitation in the dry season or the volume of rainfall in the dry season (VRD). Furthermore, we included rules to maximize this renewable resource in our analyses.

Third, drought factors were included in the analyses. These help to determine the amount of water that must be stored in order to ensure supply over a period of drought. We used two drought factors. The first, "drought in the rainy season," was used to determine the required capacity of water storage tanks to overcome drought periods in the rainy season (periods of drought within the rainy season are commonly called "Ba Chang" in Vietnamese). The second, "drought over the hydrological year," was again used to determine the reservoir capacity needed to meet water demand in the event of a drought occurring at some point during the hydrological year.

\section{Database and Methods}

\subsection{Database}

Daily rainfall data for this study was provided by measurements from 104 observation stations across the VMD and vicinity. Of these, 15 were located at meteorological stations, which also offered complete data on wind, evaporation, heat, and humidity. Besides, 29 rain gauges were located at hydrological monitoring stations, and 66 rain gauges were scattered throughout the VMD. Within the 
study area, there were 66 rain gauges, including 7 at meteorological stations and 18 at hydrological stations. Figure 1 shows the locations of the rain gauges and meteorological stations.

The lengths of the rainfall monitoring time series were not uniform and ranged from 17 to 62 years. The stations at My Tho, Go Cong Dong, Soc Trang, Ca Mau, Rach Gia, and Phu Quoc provided continuous data starting from 1975 or earlier. The time periods for which continuous data were available ranged from 43 to 67 years. To ensure uniformity, we chose to study the time period from 1989 to 2017. For this period, data were available from 90 time-synchronized monitoring stations. These data allowed analysis of the spatial distribution of rainfall. To investigate changes over time, we used data from the stations at My Tho, Soc Trang, Ca Mau, and Rach Gia.

To check the reliability of all data used in the study, we employed the $T$-test method. We tested for homogeneity using the one-sided test. The results of these analyses and examination of the data led us to remove two stations (Phu Tan and Giong Trom), due to lack of uniformity of their annual rainfall distributions. This left 102 stations for inclusion in the computational analyses.

\subsection{Methods}

The methodology flowchart is presented in Figure 2 to describe the steps this study used to explore rainfall distributions. Based on the daily rainfall data with the 1989-2017 period from 102 gauge stations, we carried out three types of analysis: (i) rainy season, (ii) rainfall volume, and (iii) drought. For the rainy season analysis, the ORD, the CRD, and the LRS were identified. For the rainfall volume analysis, we determined the distributions of rainfall volumes in temporal and spatial terms. For the analysis of the drought, the largest number of consecutive days without rain in a year (NRY) and the largest number of consecutive days without rain in the rainy season (NRW) were considered.

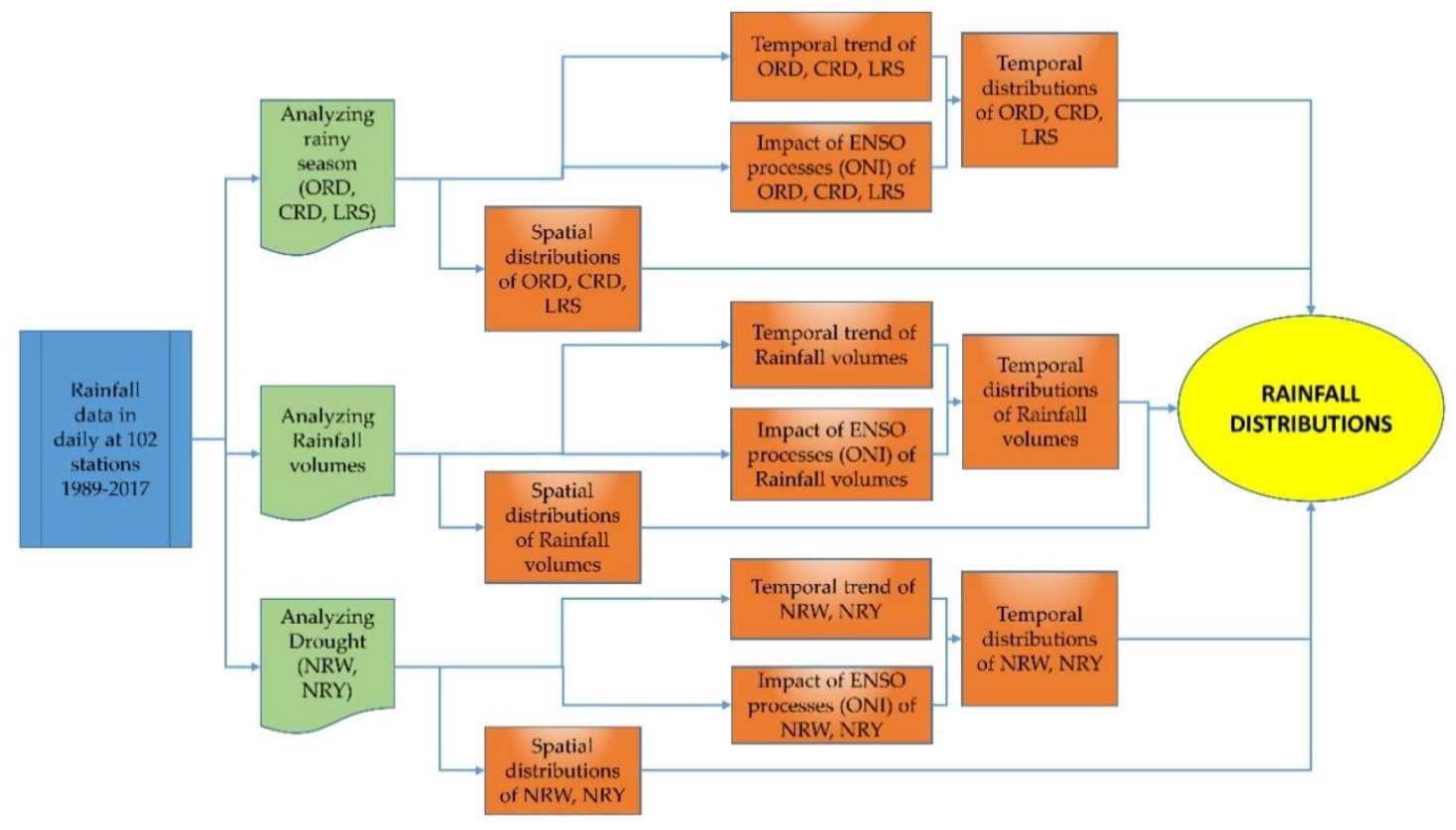

Figure 2. Methodology flowchart.

It is important to identify exact starting and end dates of a rainy season for a particular area. The identification is especially useful for drawing a plan for rainwater harvesting. The beginning of the rainy season helps to know whether the entire rainwater harvesting system needs maintenance before the start of the rainy season or not. Especially, cleaning the rooftop is required to flush away the contaminants accumulated during the dry season. The end date of the rainy season helps to know the design of rainwater storage tanks. Due to the available volume of the tanks, rainwater use is different in the rainy and dry seasons. During the rainy season, rainwater storage is used for most 
needs, while during the dry season, rainwater storage is only used for basic needs. However, this study does not aim to work with such detailed calculations, which need to be elaborated by further studies of designing rainwater storage tanks.

The date of onset of the rainy season (ORD) indicates the start of a period in which more abundant rainfall occurs more frequently [20]. Due to atmospheric instability in the intervening season, ORD is often difficult to pinpoint. In the VMD, the first rains are usually followed by short periods without rain, which also leads to difficulties in ORD determination, as dry periods within the rainy season may be difficult to distinguish from when the rainy season has not yet begun. A variety of approaches have been used to determine the date of onset of the rainy season, with the different methods yielding different ORD values. Procedures are generally consistent in the amount of precipitation they require, but differ in regard to precipitation duration.

We determined ORD using a three-pronged approach. First, we looked at the date on which accumulated rainfall reached a certain percentage of the total annual rainfall. Second, we identified the period in which average rainfall (weeks and months) exceeded the cumulative amount of evaporation during that period [18]; this is a common approach for agriculture-related purposes. Third, we looked at when the amount of rainfall measured in one day or the total cumulative amount of rainfall on consecutive days reached a certain threshold. These methods are appropriate for forecasting and production planning as well as for estimating the potential of rainwater harvesting systems for domestic uses. A number of indicators have been proposed to determine the starting date of the rainy season under conditions like those in Vietnam $[13,15,20,21]$. Those used in the current study are based on S-S [21] and S-Z indicators [15].

For our study area and time frame, use of both methods generally yielded similar ORD values. However, in a few cases, the S-Z indicator yielded an ORD much later than the S-S indicator. We, therefore, recommend use of the S-S indicator to determine ORD for the study area. According to the S-S indicator, the rainy season starts when the following conditions are met simultaneously: total rainfall on 5 consecutive days must be greater than $25 \mathrm{~mm}$; on the starting day and on at least 2 of 5 consecutive days, daily rainfall must be greater than $0.1 \mathrm{~mm}$ per day; and there must be no more than 7 consecutive days without rain. Regarding the S-Z indicator, rainfall data series needs to be smoothed by a 5-day moving average method before being used for calculation. On the basis of this new data series, the starting date must simultaneously satisfy the following conditions: five consecutive days from the starting date must have a rainfall of over $5 \mathrm{~mm}$ per day and there must be at least 10 days with a rainfall of $5 \mathrm{~mm}$ per day within the next 20 days from the starting date.

Regarding the date of cessation of the rainy season (CRD), a few studies have identified methods to compute this for the study area. The criteria for determining CRD are generally understood to be the opposite of the ORD criteria. However, that interpretation can present difficulties in distinguishing CRD from drought periods within the rainy season, especially when drought occurs near the end of a rainy season. We defined CRD as the starting date of the dry season following the last rainy season of the year. To distinguish drought periods within the rainy season ("Ba Chang" in Vietnamese), we established the following criteria: the first day of a drought period is a day without rain in the rainy season, and a drought within the rainy season is said to occur if total rainfall is less than $35 \mathrm{~mm}$ over the next 7 days. The end date of a drought period is defined as that on which more than $5 \mathrm{~mm}$ of rain falls in a single day, and over the next 7-day, rainfall is greater than $35 \mathrm{~mm}$, with at least 4 rainy days (0.1 mm).

To calculate the length of the rainy season (LRS), the following formula was used:

$$
\mathrm{LRS}_{i}=\mathrm{CRD}_{i}-\mathrm{ORD}_{i}
$$

where $i$ is the year to which the calculation pertains.

Rainfall volumes were determined based on daily observation data from the gauging stations. Annual rainfall was thus calculated as the sum of the rainfall observations on all the days of the year. Total rainfall was also calculated for four points in time, in the dry season months of January, February, 
March, and April. This was to provide more information on the potential for rainwater harvesting for use in the driest period of the year.

Drought is a phenomenon in which water shortages occur due to a lack of rain over an extended period of time with depletion of water stores. Many approaches and perspectives are available for assessing drought, depending on the level and purpose of the assessment. As the current study's objective was to perform water balance calculations to investigate the potential of rainwater harvesting in the study area, we defined drought as a continuous period with little or no rain, taking $5 \mathrm{~mm}$ as the minimum amount of rainfall needed for gainful exploitation. We studied changes in drought occurrence and duration by examining numbers of consecutive days without rain both over the year and within the rainy season.

The largest number of consecutive days without rain in a year (NRY) was determined per hydrological year [22]. This was to understand the potential of water harvesting systems to meet basic domestic needs, such as drinking, food preparation, and sanitation. Similarly, the largest number of consecutive days without rain in the rainy season (NRW) was determined. Again, this parameter is indicative of the potential of water harvesting systems to meet demands for water.

To analyze the spatial distribution of the key characteristics of rainfall in the study area, we used the rainfall data to build a matrix with a $1 \mathrm{~km}$ grid. Since local factors greatly influence rainfall characteristics, we used the inverse distance squared interpolation method, which many studies have confirmed as a very good method for rainfall distribution classification [23-25]. We created study area maps reflecting the frequency of years with little rainfall (75\%), average rainfall (50\%), and abundant rainfall (25\%) for the time period under study, thus from 1989 to 2017. To produce gridded maps of precipitation, the interpolation results of the inverse distance weighting (IDW) power 2 were used due to its higher performance, after both the methods of IWD power 1 and power 2 were validated. For the study area, WGS84-UTM $48 \mathrm{~N}$ has been used as the map projection coordinate system.

Regarding temporal trends in rainfall characteristics, we analyzed these based on averaged data for the whole region, for the subregions, for each province and for each gauging station. The nonparametric method was applied to determine trend lines [26], using the Mann-Kendall (M-K) test and Sen's slope estimation. The M-K test is often used in meteorology and hydrology $[27,28]$. The method has the advantage of being unaffected by sample values, distribution types, and so on [29-31]. When the M-K method is used to identify change trends, the long-term data series is considered as an independent sample dataset. When the number of samples is greater than eight, the standard statistical quantity $Z$ follows a normal distribution. The calculation is as follows:

$$
Z=\left\{\begin{array}{c}
\frac{S-1}{\sigma} \text { if } S>0 \\
0 \text { if } S=0 \\
\frac{S+1}{\sigma} \text { if } S<0
\end{array}\right.
$$

where $S$ and the variance $\sigma$ are determined by:

$$
\begin{gathered}
S=\sum_{i=1}^{n-1} \sum_{j=i+1}^{n} \operatorname{sign}\left(X_{j}-X_{i}\right) \\
\operatorname{sign}=\left\{\begin{array}{c}
+1 \ldots \ldots \theta>0 \\
0 \ldots . \theta=0 \\
-1 \ldots \ldots \theta<0
\end{array}\right. \\
\sigma^{2}=\frac{n(n-1)(2 n+5)}{18}
\end{gathered}
$$

The "null" hypothesis is that there is no trend in the series, and this is rejected if the calculated $Z$ is greater than the critical value $Z \alpha$, with $\alpha$ being the significance level chosen. At the $5 \%$ significance level, the hypothesis is not rejected if $Z<1.96$. At the $10 \%$ significance level, it is not rejected if $Z<1.645$. 
For Sen's slope [32], we used Sen's estimation method to determine the magnitude $Q$ of the trend of the chain:

$$
Q=\operatorname{Median}\left(\frac{X_{j}-X_{k}}{j-k}\right) \text { with } i=1, \ldots \ldots N
$$

where $x_{j}$ and $x_{k}$ are values at times $j$ and $k(j>k)$, respectively. When $Q>0$, the trend is increasing, and vice versa. Tables A2 and A3 in the Appendix A present the results of the M-K test and Sen's slope estimation for all calculations in this study.

Before the trends and change point analysis, all-time series of rainfall data were checked for autocorrelation [33,34]. Therefore, lag-1 and lag-2 autocorrelation coefficient was computed using EViews statistical software (EViews is a statistical package, which is used mainly for time-series oriented analysis [35]), and the "null" hypothesis that the serial coefficient (AC) equals to 0 is examined against the alternative hypothesis that the AC is greater than 0 , with a significance level of $5 \%$ considered. It was shown that all rainfall time series were not significantly autocorrelated at lag- 1 at $5 \%$ level (for all $p$-values $<0.05)$. The same results have been found by [36,37] for their studies on assessing rainfall data in the Vietnamese regions. Since all rainfall time series were not significantly autocorrelated, the nonparametric Mann-Kendall test and Pettitt test were used. The results are presented in the Appendix A (Table A4).

The impact of ENSO processes was also analyzed, as the study area is located in the convergence zone of monsoon systems and is strongly influenced by changes in atmospheric and ocean conditions, including those associated with ENSO processes. Because of their strong impact, many studies have examined ENSO processes and their effects [38,39]. To measure ENSO processes, we used the Oceanic Niño Index (ONI) of the NOAA Climate Prediction Center (CFC). These data were taken from the CPC website (https://origin.cpc.ncep.noaa.gov/products/analysis_monitoring/ensostuff/ONI_v5.php), which is updated on the first Thursday of each month. When ONI is less than -0.5 , a La Niña period is indicated; when ONI is between -0.5 and 0.5 , it is a neutral period; and when ONI is greater than 0.5 , an El Niño period is indicated. To determine impacts of ENSO processes, we investigated relationships between ONI and rainfall characteristics in the study area.

Breakpoint detection method: This study detected breakpoints of various time-series data by using experimental trial test which was also double-checked with Pettitt test [40]. The method was as follows:

- For time-series data available from 1989-2017, observing the peak value of rainfall and the beginning of the rainy season in the study area appeared in 1999. Hence, the study used the year of 1999 as a change point to consider changes in characteristics over time.

- For longer time-series data of four gauging stations of Rach Gia, Ca Mau, Soc Trang, and My Tho: the years of 2000-2017 is still considered as a period. For the period from 1999 to earlier, the year of 1999 was taken as the end year, and we tried each year until the M-K test was used to confirm the trends. Results for trend confirmation were found as Rach Gia from 1986 (significance level $P=9.44 \%)$, Ca Mau from $1981(P=0.4 \%)$, Soc Trang from $1987(P=0.9 \%)$, and My Tho from 1978 $(P=1.4 \%)$.

Our results of breakpoint detection for the ORD, CRD, and LRS and rainfall trends are presented in Section 4.2.2.

\section{Results and Discussion}

\subsection{Rainfall Characteristics in the Coastal Provinces of the VMD}

\subsubsection{Spatial Distribution}

Figure 3 presents distribution maps for ORD, CRD, and LRS corresponding to the average year (50\% frequency). Table A1 in the Appendix A presents the associated values. In general, the distribution characteristics were consistent with a southwest wind direction. The rainy season starts earlier, ends 
later, and lasts longer on the west coast, which is exposed to southwesterly winds. These effects decrease both inland and towards the East Sea.
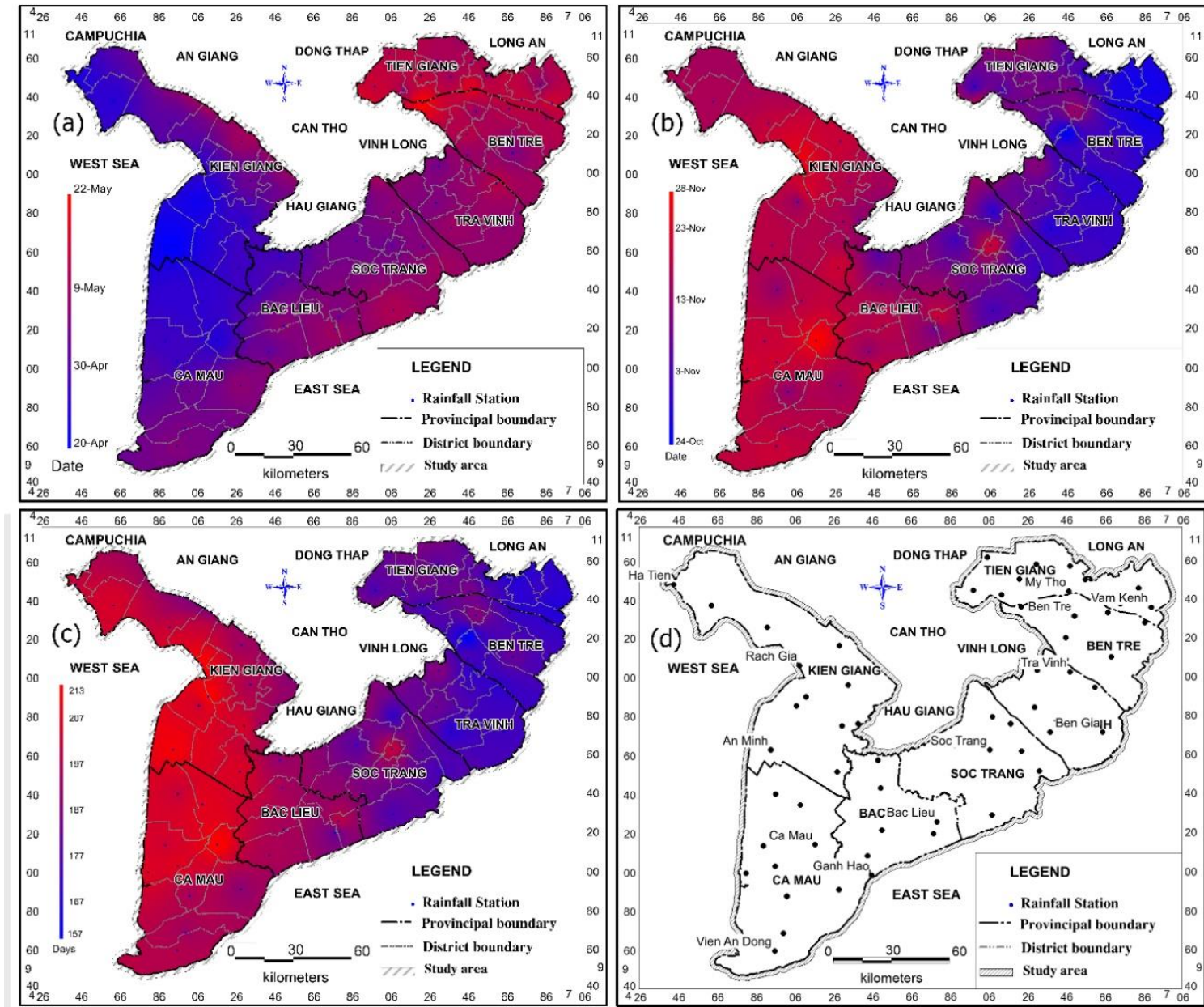

Figure 3. Distribution maps representing the average year (50\%) of (a) ORD, (b) CRD, (c) LRS, and (d) monitoring stations in the coastal provinces of the Vietnamese Mekong Delta (VMD).

The average ORD in the study area was May 4, with a standard deviation of 11 days, which is relatively the same with the research finding of 13 days of [41]. The earliest ORDs were found in Kien Giang and Ca Mau provinces (28-30 April). The latest ORDs were in Ben Tre and Tien Giang (11-13 May). ORD differed up to 15 days between the earliest and latest provinces. For the study area as a whole, the difference between ORDs for each of the three probability cases-early rain $(25 \%)$, average rain $(50 \%)$, and late rain $(75 \%)$ - was about 12 days.

The CRD tendency was generally the opposite that of ORD; that is, while the rainy season tended to come early, it ended late. Moreover, the rainy season ended later on the west coast than on the East Sea coast. The earliest CRD was found in Ben Tre (1 November), and the latest was in Ca Mau (18 November). The average CRD for the region as a whole was 11 November, with a standard deviation of 11 days. The earliest CRD in the estuary area was 2 November, while the latest was found in LXQ (17 November). Comparing the provinces, the average difference in CRD between the year with the most rainfall and that with average rainfall was 17 days. Comparing the average rainfall year with the year having the least rainfall, the difference in CRD between the provinces averaged 12-13 days, as also found by [41].

For LRS, a similar distribution rule was found as for ORD and CRD. The length of the rainy season was much greater on the western coast than inland and the eastern coast which is similar to the findings of [42] for the highest rainfall distribution found in Ca Mau. For the study area as a whole, 
LRS averaged about 190 days, with a standard deviation of 16 days. Ca Mau and Kien Giang had the longest rainy seasons (LRS $=201$ days), whereas Ben Tre had the shortest LRS (174 days). Compared to the average year, LRS in rainy years averaged 19 days longer, whereas LRS was 17 days shorter in the less rainy years. These high LRS numbers point to substantial potential for rainwater harvesting in the study area, though spatial and temporal variabilities may pose constraints. Overall, the LRS found is average in the study area compared to other coastal data worldwide, i.e., 129 days found in general Asia region by [43] and 210-220 days found in Ghana, Africa, by [44].

\subsubsection{Temporal Distribution}

Figure 4 presents ORD, CRD, and LRS for the entire study area and for our three subregions.
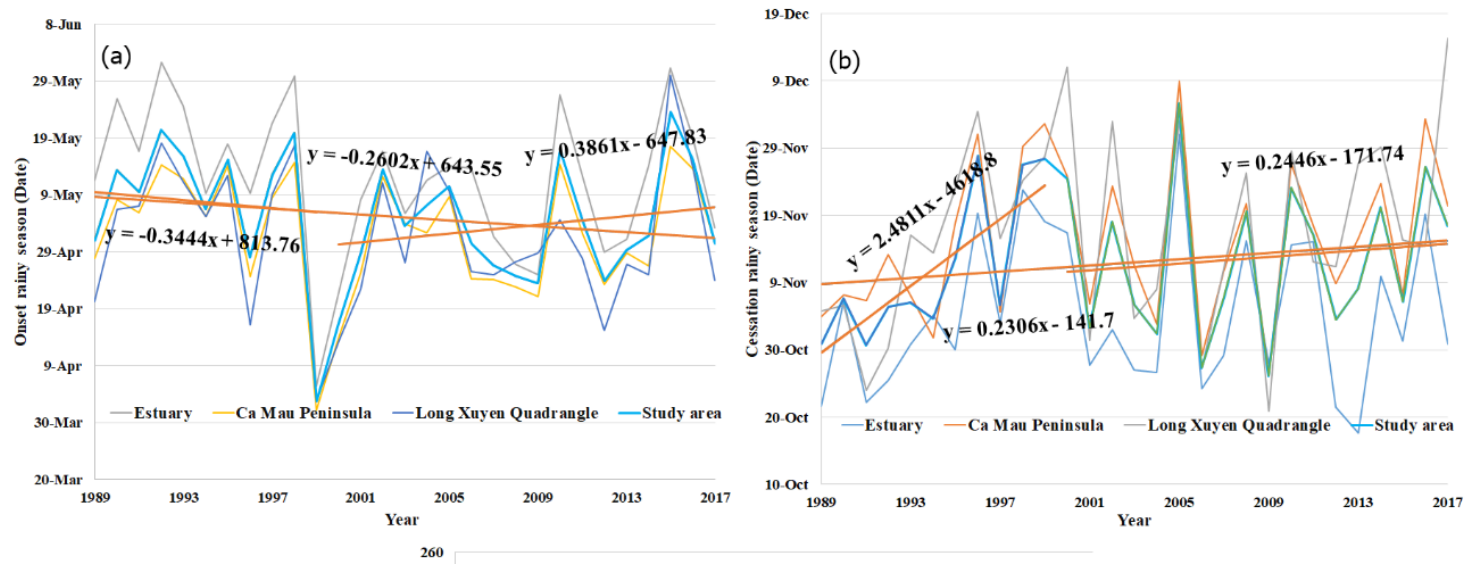

(c)

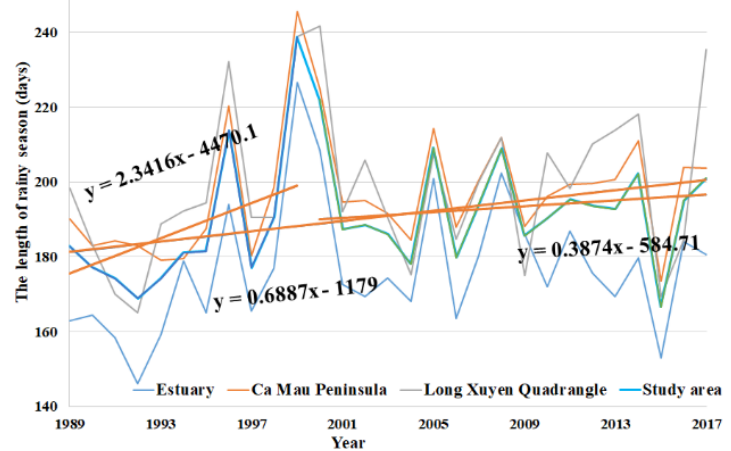

Figure 4. The date of onset of the rainy season (ORD) (a), the cessation date of the rainy season (CRD) (b), and the length of the rainy season (LRS) (c) for the entire study area and for the estuary, CMP, and LXQ subregions.

The data show 1999 to be the year with the earliest rainy season. Moreover, in that year, the rainy season ended late, making it the lengthiest rainy season in the data series. The general trend for the whole period (1989-2017) shows that ORD decreased slightly (shifting earlier) and CRD increased slightly (shifting later), leading to an increase in LRS. From 1989 to 1999, ORD decreased by an average of 0.34 days per year and CRD increased by an average of 2.48 days per year, causing a sharp increase, averaging 2.34 days, in LRS per year. However, after 1999, the trend changed. At this time, ORD began to increase at a rate of 0.39 days per year on average. CRD continued its upward trend, but at a slower rate (0.24 days per year on average). LRS also began a downturn (at a rate of 0.39 days per year on average).

Trends in the period 1989-1999 were found to be highly reliable, with the verification results confirming reliability at $5 \%$ or $10 \%$ significance level, depending on the region. Trend reliability was very low for the study period as a whole (1989-2017) and for 2000-2017. 


\subsubsection{Impacts of the ENSO Processes}

Figure 5 presents the relationship between ONI and rainy season characteristics; La Niña years are those in which $\mathrm{ONI}<-0.5$, on the left of the blue border and in the direction of the blue arrow, whereas El Niño years are the years in which ONI $>0.5$, on the right of the red boundary and in the direction of the red arrow.

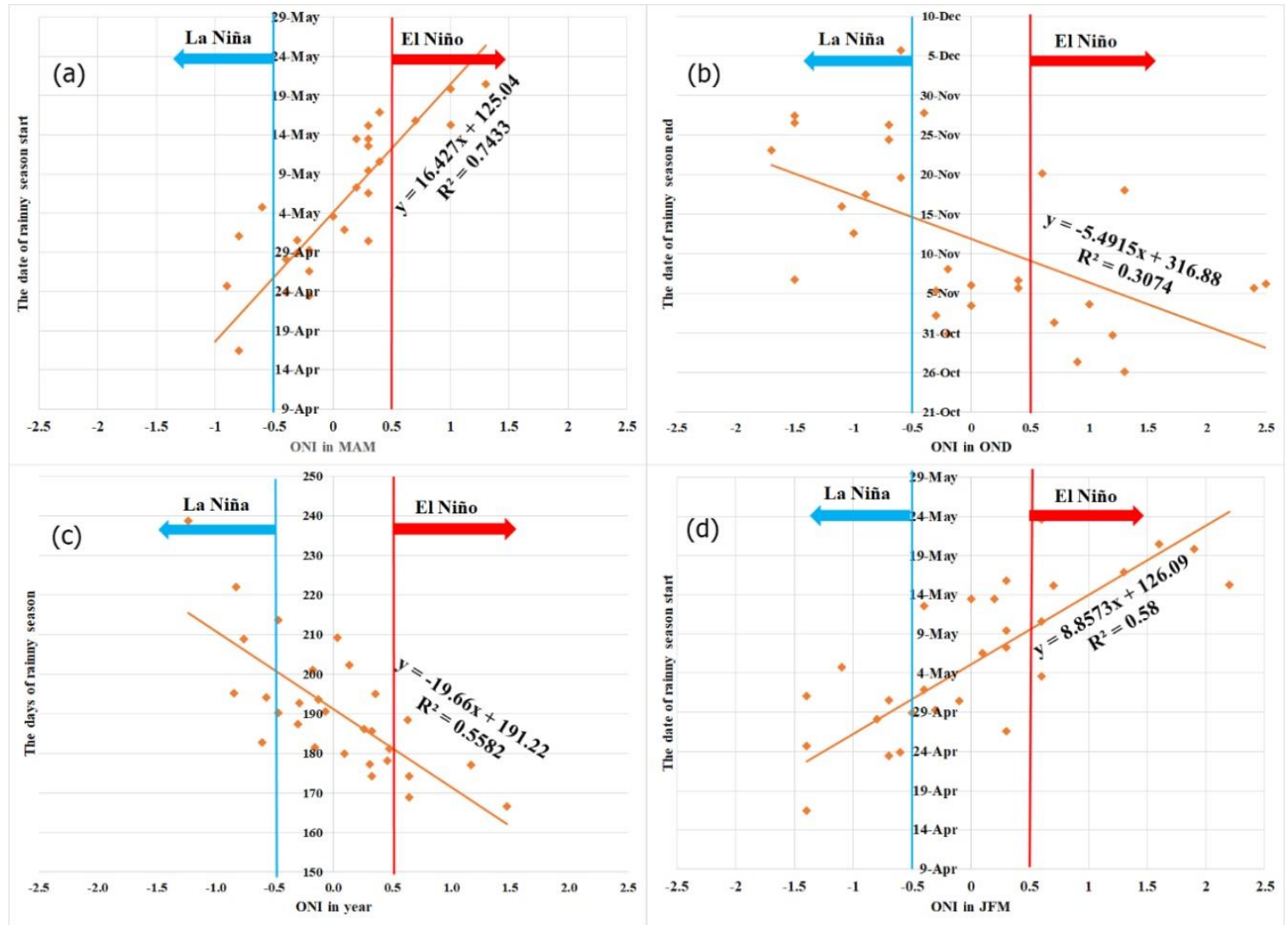

Figure 5. Relationship between ONI and rainy season characteristics: (a) relationship between ONI in April and the rainy season start date, (b) relationship between ONI in November and the end of the rainy season, (c) the relationship between the average annual ONI and the length of the rainy season, and (d) the relationship between ONI in February and the start date of the rainy season.

The results show a close correlation between the start date of the rainy season and ONI in MAM $\left(R^{2}=0.743\right)$. The relationship between the length of the rainy season and the annual average ONI was also relatively tight $\left(R^{2}=0.558\right)$. A relationship was also found between the end date of the rainy season and ONI in OND. However, this relationship was weaker $\left(R^{2}=0.307\right)$. ORD was found to be strongly correlated with ONI in JFM $\left(R^{2}=0.580\right)$, indicating that the ONI in JFM could be relied upon to forecast the beginning of the rainy season. This is relevant to the findings of [16] on the correlations between heavy monthly rainfall in Vietnam and the ONI.

\subsection{Rainfall}

\subsubsection{Distribution Characteristics of Rainfall}

Figure 6 presents a rainfall distribution map for the average year (50\%). Table 1 presents the annual distribution of rainfall and rainfall during the four dry season months in the coastal provinces. 


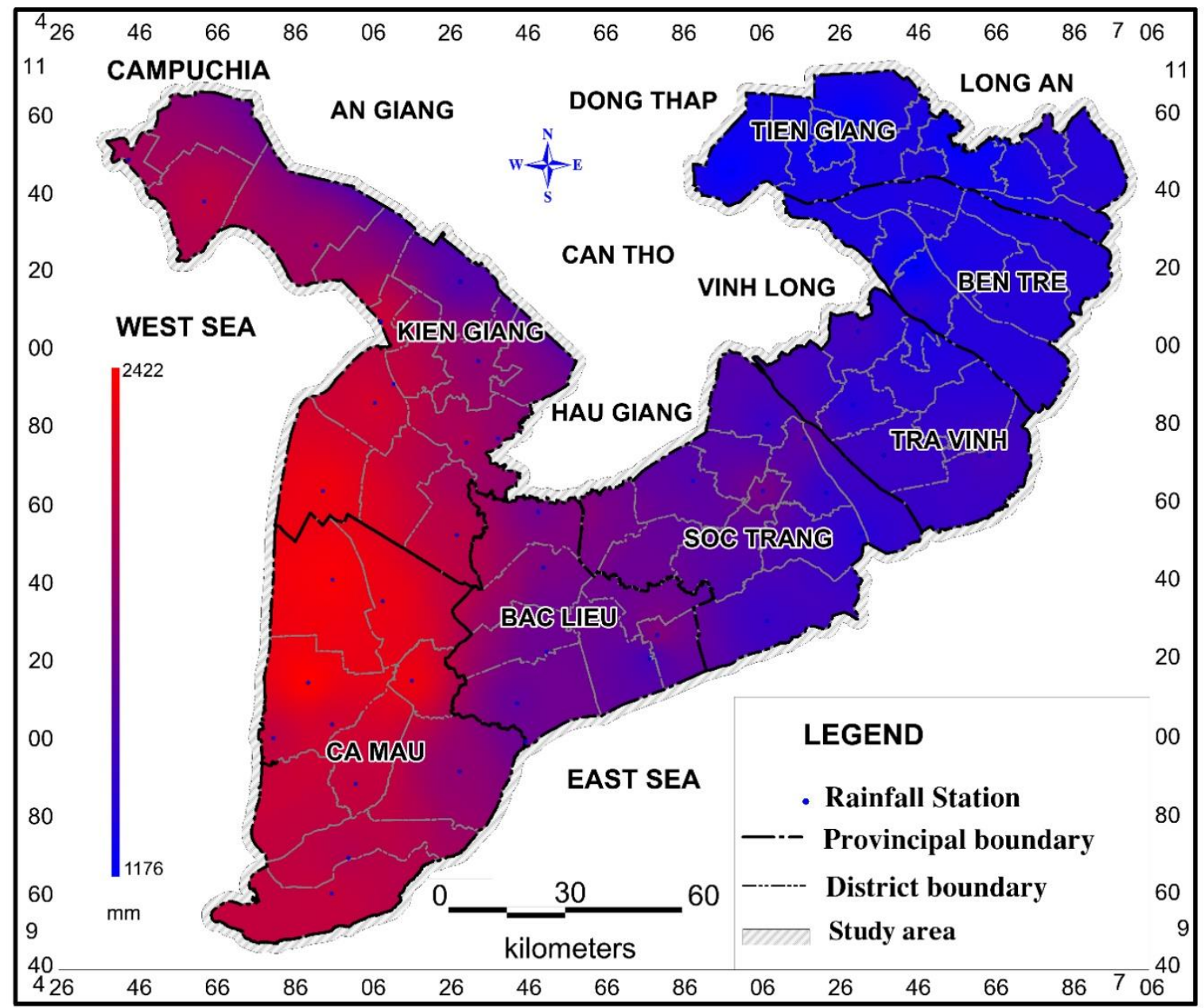

Figure 6. Annual distribution of rainfall in coastal provinces of the VMD in the average year (50\%).

Table 1. Data on annual rainfall and rainfall in the four dry season months in coastal provinces of the Vietnamese Mekong Delta (VMD), according to rain gauge data, 1989-2017.

\begin{tabular}{|c|c|c|c|c|c|c|c|c|c|}
\hline & Province & Tien Giang & Ben Tre & Tre Vinh & Soc Trang & Bac Lieu & Ca Mau & Kien Giang & Study Area \\
\hline \multirow{4}{*}{ 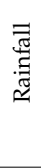 } & Area $\left(\mathrm{km}^{2}\right)$ & 2477 & 2403 & 2426 & 3600 & 2681 & 5243 & 5646 & 24,476 \\
\hline & Population $\left(10^{3}\right.$ people $)$ & 1752 & 1267 & 1046 & 1314 & 894 & 1226 & 1793 & 9291 \\
\hline & Housing area $\left(\mathrm{m}^{2} /\right.$ person $)$ & 28.5 & 28.4 & 23.7 & 20.4 & 19.0 & 21.4 & 20.0 & 23.4 \\
\hline & Water demand $\left(10^{6} \mathrm{~m}^{3} /\right.$ year $)$ & 1814 & 540 & 1741 & 3042 & 1188 & 1236 & 5216 & 14,777 \\
\hline \multirow{7}{*}{  } & Average (mm) & 1439 & 1485 & 1584 & 1716 & 1921 & 2247 & 2028 & 1860 \\
\hline & Min & 1118 & 1159 & 1251 & 1290 & 1543 & 1908 & 1567 & 1556 \\
\hline & $\operatorname{Max}$ & 1835 & 1858 & 2108 & 2339 & 2566 & 2906 & 2653 & 2427 \\
\hline & $\mathrm{CV}$ & 0.14 & 0.13 & 0.13 & 0.13 & 0.13 & 0.11 & 0.12 & 0.11 \\
\hline & Cs & 0.17 & 0.12 & 0.54 & 0.67 & 0.54 & 1.43 & 0.81 & 0.82 \\
\hline & Median & 1442 & 1463 & 1545 & 1709 & 1889 & 2199 & 2013 & 1859 \\
\hline & Standard deviation & 196 & 186 & 202 & 217 & 250 & 236 & 238 & 199 \\
\hline \multirow{7}{*}{ 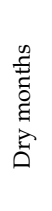 } & Average $(\mathrm{mm})$ & 66 & 57 & 62 & 81 & 105 & 136 & 156 & 107 \\
\hline & Min & 6 & 3 & 1 & 4 & 2 & 8 & 11 & 7 \\
\hline & Max & 285 & 264 & 265 & 371 & 456 & 501 & 512 & 411 \\
\hline & $\mathrm{CV}$ & 0.92 & 1.01 & 0.97 & 1.02 & 0.94 & 0.81 & 0.72 & 0.81 \\
\hline & Cs & 1.74 & 1.94 & 1.69 & 2.03 & 1.82 & 1.38 & 1.32 & 1.69 \\
\hline & Median & 65 & 40 & 34 & 50 & 79 & 117 & 135 & 83 \\
\hline & Standard deviation & 61 & 58 & 61 & 83 & 99 & 111 & 112 & 87 \\
\hline
\end{tabular}

Our results show substantial variation in annual rainfall volumes across the study area. Rainfall was concentrated along the West Sea coast, centered in the U Minh area, and decreasing towards the East Sea and inland. This rainfall distribution is consistent with the ORD distribution. Average rainfall was $1860 \mathrm{~mm}$, with the lowest amounts registered in Tien Giang (1439 mm) and the highest amounts 
in Ca Mau (2247 mm). The coefficient of variation (CV) varied from 0.11 to 0.14 , though the average value was not very different from the median value. This demonstrates that annual rainfall fluctuation in the study area was not significant.

In the 4 months of the dry season, rainfall was still quite abundant, averaging $107 \mathrm{~mm}$. The highest amounts were registered in Kien Giang $(156 \mathrm{~mm})$ and Ca Mau (136 mm). In many years, dry season rainfall reached $411 \mathrm{~mm}$ for the region as a whole, $512 \mathrm{~mm}$ in Kien Giang, and $501 \mathrm{~mm}$ for Ca Mau. This represents a large amount of water distributed in a period when freshwater is most difficult to access, suggesting the possibility of taking advantage of these rainfalls for exploitation. However, rainfall during the dry season was unpredictable; $\mathrm{CV}$ ranged from 0.72 to 1.02 confirming the volatility of this resource. In many cases, dry season rainfall is too minimal to be exploited. Due to this volatility, dry season rainfall can hardly be considered a dependable source for essential provisions, though it could be used to complement other sources.

To investigate the potential of rainwater harvesting to serve local demand, general information on area and population, freshwater demands, and housing were taken from the 2017 Yearbook of Coastal Provinces and [45]. Population and housing census figures refer to 2019 [46].

Across the study area as a whole, total annual rainfall averaged 45.5 billion $\mathrm{m}^{3}$ per year. This was $4900 \mathrm{~m}^{3}$ per capita per year greater than the average in Vietnam, and more than the average for Southeast Asian countries [47]. Even in the year with the least rainfall, more than 38 billion $\mathrm{m}^{3}$ of rain was recorded ( $4099 \mathrm{~m}^{3}$ per capita). This was 2.57 times higher than total freshwater demand in the coastal provinces.

The province with the highest rainfall was $\mathrm{Ca} \mathrm{Mau}$, which was also the province furthest from the

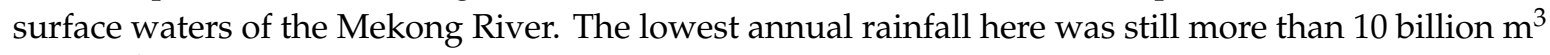
(8158 $\mathrm{m}^{3}$ per capita), which is more than eight times greater than demand. The estuarine provinces, which had easy access to Mekong River surface waters, had the lowest rainfall, but rainfall was still relatively abundant even here. Tien Giang had the lowest annual rainfall of all the provinces in the study area, though this was still 2.77 billion $\mathrm{m}^{3}$ per year, 1.53 times greater than demand (1582 $\mathrm{m}^{3}$ per capita).

While rainfall in the study area was plentiful, and sufficient to meet use demands, rain can be contaminated by the quality of the surface it falls upon. Water harvesting systems, therefore, need clean, easy-to-handle surfaces to collect and maintain fresh water. Traditionally in the study area, water for domestic purposes is collected from the roof. This study therefore estimated the water collection area (roof area) as equivalent to the area of housing in the provinces. This provided an indication of the potential area available to collect rainwater for day-to-day domestic use.

On average, the amount of rain falling onto a roof during the year reached $43 \mathrm{~m}^{3}$ per capita, equivalent to $119 \mathrm{~L}$ per capita per day. In the driest period of the year, the amount of water that could be collected was still $36.4 \mathrm{~m}^{3}$ per capita per year, equivalent to $99.7 \mathrm{~L}$ per capita per day. This is much more water than currently used in rural areas. Tien Giang, the province with the least rainfall, still registered $31.86 \mathrm{~m}^{3}$ per capita in the driest year. This is equivalent to $87 \mathrm{~L}$ per capita per day. In $\mathrm{Ca} \mathrm{Mau}$, the province from which it was most difficult to access freshwater from the Mekong River, rainfall collected from roofs in the driest part of the year amounted to $40.8 \mathrm{~m}^{3}$ per capita, equivalent to 112 L per capita per day.

In general, rainfall in the study area was plentiful and sufficient to meet water use demands. In the conditions observed at the time of this study, rainwater collected from the roof could be sufficient to meet domestic demands, assuming a standard of 80 L per capita per day [48].

\subsubsection{Rainfall Trends}

Figure 7 presents annual precipitation volumes for the 1989-2017 period for the study area as a whole and for the three subregions, and Figure 8 presents precipitation trends for selected gauging stations. In general, the most stable averages were found for the study area as a whole. Rainfall in LXQ decreased slightly, and rainfall in the estuarine zone increased slightly. Little change was found for CMP. 

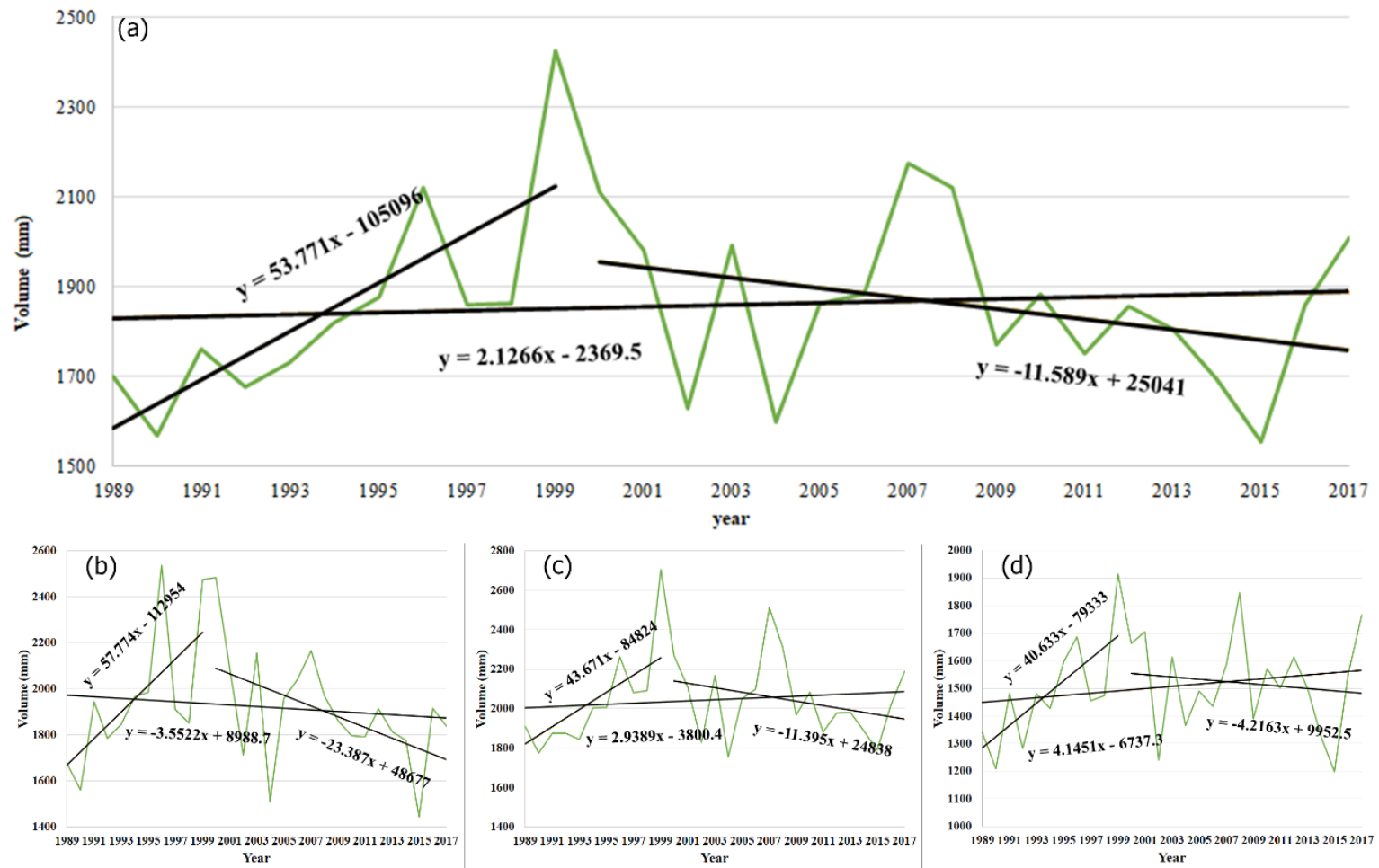

Figure 7. Trends in annual rainfall patterns from 1989 to 2017: (a) the study area, (b) LXQ, (c) CMP, and (d) the estuaries.
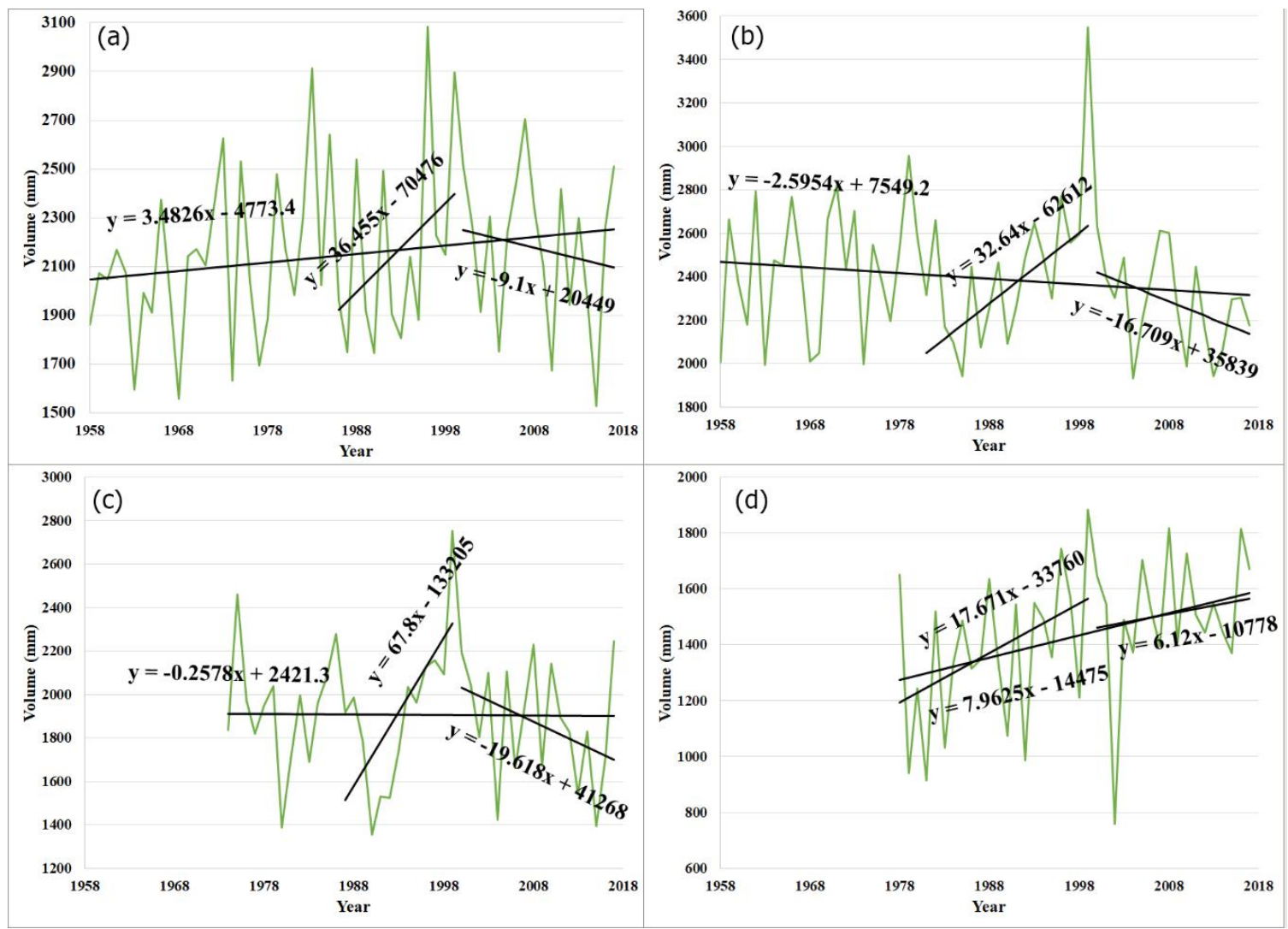

Figure 8. Trends in annual precipitation at monitoring stations at (a) Rach Gia, (b) Ca Mau, (c) Soc Trang, and (d) My Tho. 
Sen's slope for the trends was quite small, and we found a very low reliability of patterns, not verified by the M-K test at the 5\% or 10\% significance level. From the graphs in Figures 7 and 8 , we see that annual rainfall volumes peaked in 1999 across the study area, and specifically, in the subregions and gauging stations. In the period 1989-1999, rainfall increased sharply across the region, including all subregions and gauging stations in the study area. The reasonably significant Sen's slope value indicates a steady upward trend in annual rainfall. The M-K test, with a significance of $5 \%$, confirms the upwards trend for the whole region and each subregion (see Tables A2 and A3 in the Appendix A).

After 1999, annual rainfall began to show a downward trend. The decrease was sharpest in LXQ, though also evident in CMP (Figure 7). In the estuarine zone, rainfall tended to decrease slightly. Similar trend lines were found for the monitoring stations: the sharp downward trend continued in Rach Gia, there was a downward trend in Ca Mau and Soc Trang, and an upwards trend continued in My Tho (Figure 8). However, the reliability of the trend lines for the period 2000-2017 could not be confirmed by the M-K test, so the reliability of the trend lines must be considered very low.

Annual rainfall in the study area was generally quite complex. On the West Sea coast, where southwest winds reach land in the study area, heavy rainfall continued. There was, however, some differentiation in trends by region. From 1980 to 1999, annual rainfall showed a clear increasing trend across the region, with high reliability. The rainfall peak was in 1999.

After 1999, rainfall trends began to differ by geographic region. The west coast area and the East Sea area at that point began to exhibit a decreasing trend. The differences across the study area in changes in annual rainfall confirm the complexity of the impacts of climate change in the study area. Specifically, climate change impacts on moisture transport directions appear to differ across the study area.

\subsubsection{Impacts of ENSO Processes on Rainfall}

Figure 9a,b shows the relation between annual rainfall volume and annual average ONI and rainfall volumes in the four dry season months and average dry season ONI. We found a correlation between both annual rainfall and dry season rainfall with ONI, but the relationship was not close, with $R^{2}=0.462$ and $R^{2}=0.456$, respectively. El Niño effects were found in some years, but rainfall was still quite high as the impacts of the ENSO reported by [43], and in contrast, rainfall was quite low in some La Niña years.

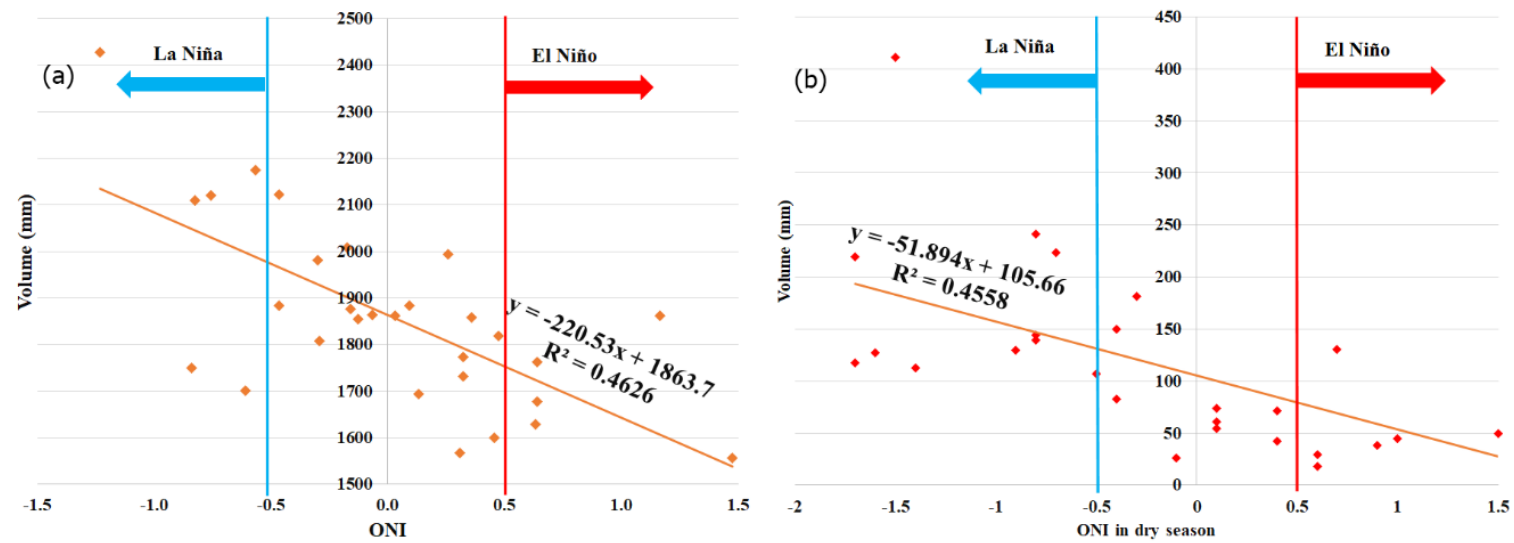

Figure 9. Relation between rainfall and ONI: (a) annual rainfall and annual average ONI and (b) rainfall in the four dry season months and average ONI in the dry season.

Dry season rainfall averaged more than $100 \mathrm{~mm}$ in La Niña years. In the El Niño years, dry season rainfall usually remained less than $100 \mathrm{~mm}$. This suggests that it is possible to plan rainwater harvesting in the dry season based on ENSO processes. 


\subsection{Number of Consecutive Nonrainy Days in Coastal Provinces}

\subsubsection{Characteristics of Rainfall Distribution}

Annual rainfall data allowed us to calculate the roof area needed to ensure collection of a sufficient amount of water for domestic use [49]. The number of consecutive nonrainy days, however, is important for determining the needed rainwater collection and storage capacity. Nevertheless, this study only considers rainfall indicators related to rainwater harvesting, for which, the details on calculations such as how reliability indices and storage volumes for rainwater tanks could be referred from [49-51]. Figure 10 presents maps of NRW and NRY for the average year (50\%). Table 2 presents statistical data for NRY and NRW.
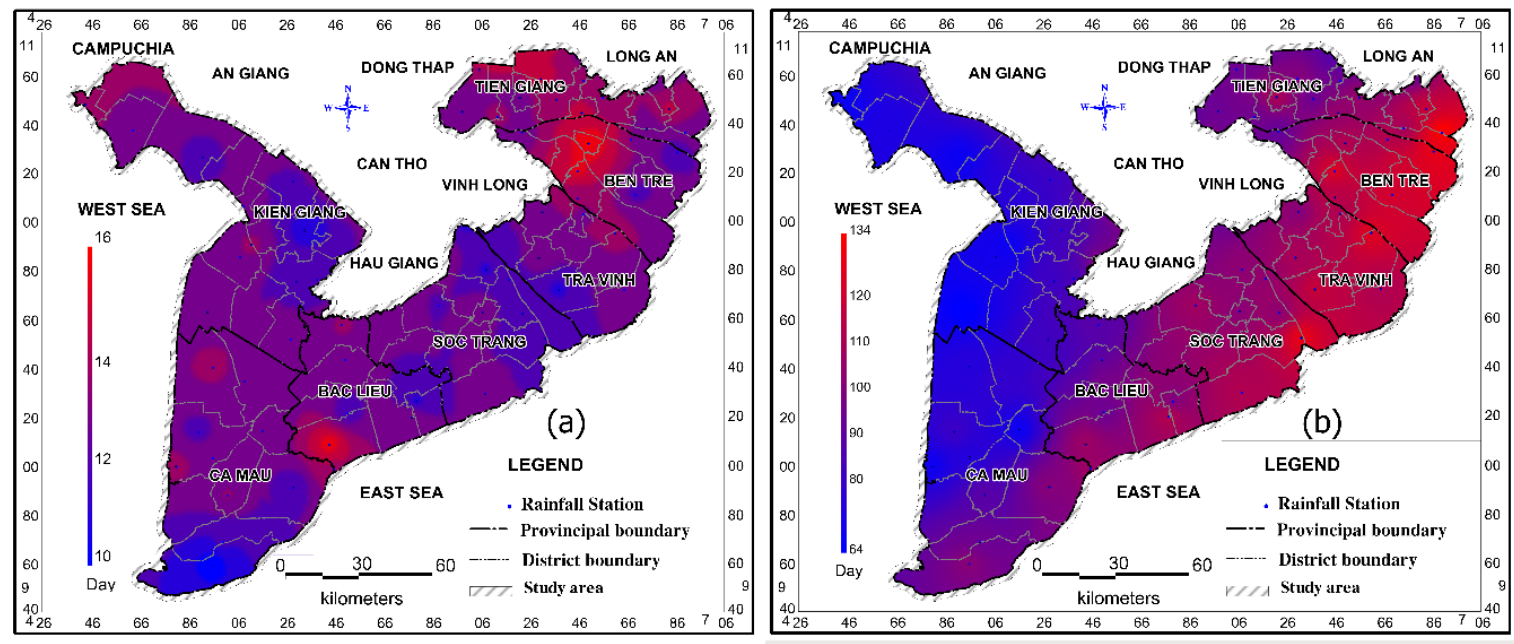

Figure 10. Number of consecutive days without more than $5 \mathrm{~mm}$ rain in the rainy season (NRW) (a) and throughout the year (NRY) (b).

Table 2. Data on the number of consecutive nonrainy days in the year (number of consecutive days without rain in a year, NRY) and during the rainy season (number of consecutive days without rain in the rainy season, NRW) in the coastal provinces of the VMD and in the study area as a whole for the 1989-2017 period.

\begin{tabular}{|c|c|c|c|c|c|c|c|c|c|c|c|c|}
\hline & Province & $\begin{array}{l}\text { Tien } \\
\text { Giang }\end{array}$ & $\begin{array}{l}\text { Ben } \\
\text { Tre }\end{array}$ & $\begin{array}{c}\text { Tra } \\
\text { Vinh }\end{array}$ & $\begin{array}{c}\text { Soc } \\
\text { Trang }\end{array}$ & $\begin{array}{c}\text { Bac } \\
\text { Lieu }\end{array}$ & $\begin{array}{c}\text { Ca } \\
\text { Mau }\end{array}$ & $\begin{array}{l}\text { Kien } \\
\text { Giang }\end{array}$ & Estuary & CMP & LXQ & $\begin{array}{c}\text { Study } \\
\text { Area }\end{array}$ \\
\hline \multirow{7}{*}{$\frac{\succsim}{\text { 乙 }}$} & Average (mm) & 112 & 121 & 120 & 114 & 104 & 91 & 85 & 117 & 98 & 86 & 103 \\
\hline & Min & 55 & 65 & 52 & 65 & 58 & 41 & 41 & 63 & 53 & 41 & 56 \\
\hline & Max & 172 & 181 & 167 & 168 & 174 & 142 & 141 & 173 & 152 & 144 & 152 \\
\hline & $\mathrm{CV}$ & 0.32 & 0.27 & 0.24 & 0.25 & 0.31 & 0.35 & 0.34 & 0.27 & 0.31 & 0.34 & 0.29 \\
\hline & Cs & 0.33 & 0.06 & $(0.09)$ & 0.05 & 0.28 & 0.10 & 0.17 & 0.20 & 0.12 & 0.20 & 0.13 \\
\hline & Mean & 102 & 121 & 122 & 108 & 104 & 84 & 85 & 106 & 97 & 84 & 106 \\
\hline & Standard deviation & 35 & 33 & 29 & 29 & 32 & 32 & 28 & 31 & 30 & 30 & 29 \\
\hline \multirow{7}{*}{$\underset{z}{z}$} & Average (mm) & 15 & 15 & 14 & 14 & 14 & 14 & 14 & 15 & 14 & 14 & 14 \\
\hline & Min & 12 & 11 & 10 & 10 & 9 & 11 & 11 & 11 & 11 & 11 & 12 \\
\hline & Max & 19 & 20 & 21 & 21 & 24 & 22 & 23 & 18 & 21 & 19 & 19 \\
\hline & $\mathrm{CV}$ & 0.13 & 0.14 & 0.18 & 0.20 & 0.23 & 0.17 & 0.15 & 0.12 & 0.14 & 0.12 & 0.11 \\
\hline & Cs & 0.21 & 0.42 & 0.53 & 1.08 & 1.71 & 1.51 & 2.92 & -0.01 & 1.57 & 0.71 & 1.20 \\
\hline & Mean & 15 & 15 & 14 & 13 & 14 & 13 & 13 & 14 & 13 & 14 & 14 \\
\hline & Standard deviation & 2 & 2 & 3 & 3 & 3 & 2 & 2 & 2 & 2 & 2 & 2 \\
\hline
\end{tabular}

We found the NRY distribution to be quite similar to the distributions of rainfall in the rainy season and throughout the year. The western coastal region, which is substantially influenced by the southwest wind, had the smallest NRY. The area with the largest NRY was the estuaries, particularly the provinces of Tien Giang, Ben Tre, and Tra Vinh. For the study area as a whole, NRY averaged 103 days (with a standard deviation of 29 days). For LXQ, NRY was 86 days, for CMP, it was 98 days, 
and for the estuaries, it was 117 days. The province of Kien Giang had the shortest NRY, at 85 days. The longest NRY was registered in Ben Tre, at 121 days. In general, NRY values showed strong spatial differentiation.

NRW showed no clear distribution pattern. NRW averaged 14 days, though little differentiation was found across the study area (NRW ranged from an average of 13-15 days). Using this annual rainfall data, we can calculate the roof area needed to harvest sufficient amounts of water for domestic use. Similarly, the number of consecutive nonrainy days can be used to determine the volume of rainwater that must be stored to provide a continuous water supply.

The coefficient of variation (CV) of NRY ranged from 0.24 to 0.35 , which is quite large, indicating high volatility of NRY. In long drought years, NRY averaged up to 152 days. The maximum number of consecutive days without rain over the year was lowest in LXQ at 144 days, followed by 152 days in CMP. NRY was greatest in the estuaries, at 173 days. Looking at the provinces, the highest NRY (thus the longest periods without rain) was registered in Ben Tre, at 181 days. Ca Mau and Kien Giang had the shortest NRY, at 142 and 141 days, respectively. In many provinces, however, the NRY plummeted over the study period. Thus, the average for the whole region was just 56 days. NRY averaged just 41 days in the provinces of Ca Mau and Kien Giang, while NRY remained the longest in Ben Tre, at 65 days.

NRW fluctuated less than NRY, with CV ranging from 0.11 to 0.23 . In drought years, NRW averaged 19 days, which is much greater than the 5-day average in normal years for the study area as a whole. The highest NRW was registered in Bac Lieu, at 24 days. The lowest was in Tien Giang, at 19 days. Years in which NRW is high can cause considerable damage to agricultural production in areas where surface water is difficult to access, especially in provinces like Ca Mau and Bac Lieu. The estuarine provinces and LXQ are less affected by years with high NRW due to their access to upstream Mekong flows.

NRY is a vital indicator for calculating the water balance for rainwater collection systems. The sharp fluctuation found for this indicator suggests difficulty in designing rainwater harvesting systems adequate to provide for domestic needs in the study area. If the number of consecutive days without rain in a year is high, large tank capacities are needed to meet domestic water requirements. Construction costs for such tanks are currently quite high. Backup water sources will, therefore, be needed, alongside solutions to lower the cost of rainwater tanks.

\subsubsection{Trends in the Drought}

Figure 11 presents the development of NRY and NRW over the study period. The graphs show no clear trend. NRY was highest in 2016 and lowest in 1999. NRW was highest in 2004 and lowest in 2012.

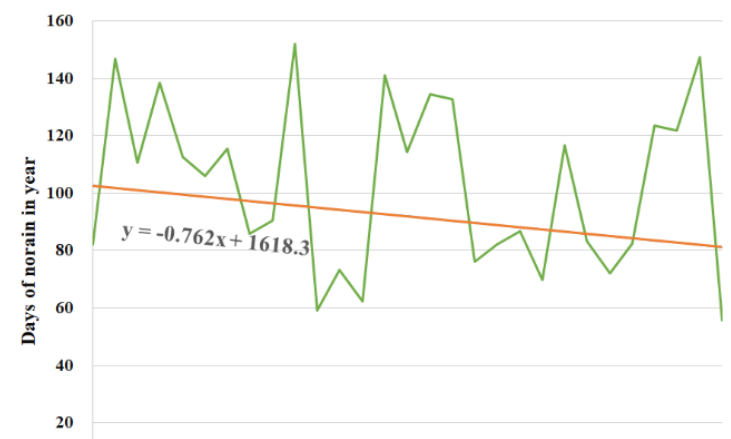

(a)

198919911993199519971999200120032005200720092011201320152017

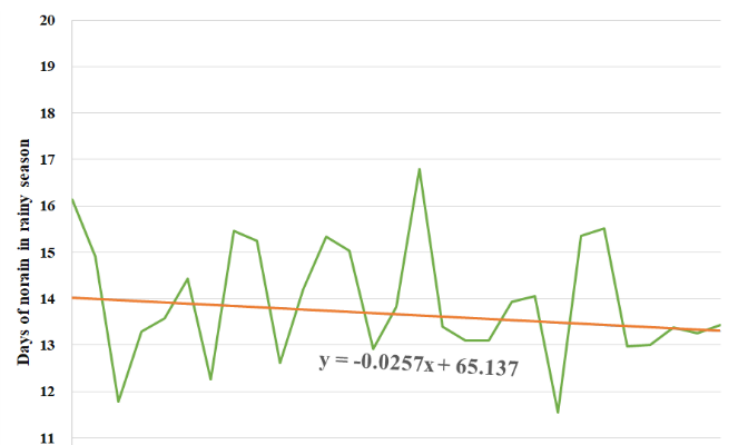

(b)

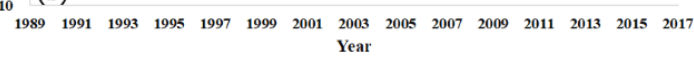

Figure 11. The number of consecutive days without rain (a) in a year and (b) in the rainy season.

M-K tests for NRY and NRW values revealed a slight downward trend in NRY and little variation in NRW. However, the reliability, here, was not significant. 


\subsubsection{Impacts of ENSO Processes on Drought}

Figure 12 presents the relationship between drought and ONI.

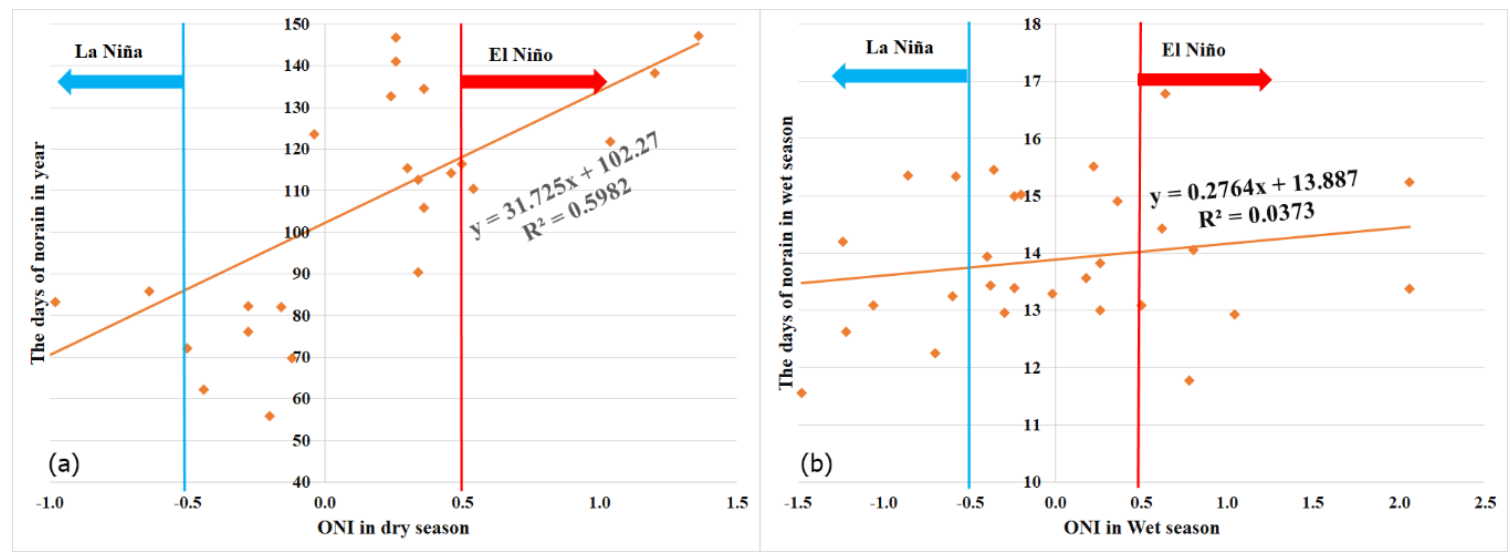

Figure 12. Relationship between drought and ONI: (a) NRY and average ONI in the dry season and

(b) NRW and average ONI in the rainy season.

The results indicate no correlation between ONI in the rainy season and the greatest number of nonrainy days in the rainy season (NRY). The correlation between the number of consecutive days without rain in the rainy season (NRW) and average ONI in the dry season was quite close $\left(R^{2}=0.598\right)$.

\section{Conclusions}

The research presented here provides a vital puzzle piece for scientists and policymakers seeking to effectively exploit rainwater in coastal areas of the Vietnamese Mekong Delta. We found changes in rain distribution over space and time related to the impacts of climate change and ENSO processes. Our findings suggest five main conclusions.

First, rainfall was quite abundant in the western coastal region of the study area, diminishing gradually towards the East Sea and inland. Rainfall was also relatively plentiful in the 4-month dry season, but it lacked the predictability needed for effective exploitation. Nonetheless, rainfall in the dry season can be considered a key supplementary source of freshwater, and it should be utilized in years of high rainfall.

Second, the NRY for the study area as a whole was 103 days, with a 29-day differential between the highest and lowest observations. The shortest time period without rainfall was 85 days, and the longest was 121 days for the average year. NRY fluctuation was quite large in both dry years and rainy years, though its spatial distribution was similar to that of annual and rainy season rainfall volumes. The volatility of NRY demonstrates the unpredictability of rainfall, necessitating a backup water source for water provision in years with exceptionally high NRY.

Third, the number of consecutive days without rain in the rainy season (NRW) averaged 14 days for the study area as a whole. NRW was quite stable in terms of space and time; the largest difference in NRW between provinces was 5 days. The difference between the average year and the year with the highest NRW was also 5 days, indicating the stability of rainfall volumes in the rainy season.

Fourth, the impact of climate change on the rainfall regime in the study area turned out to be rather complex. Our data suggest a division into two phases. In the first phase, from 1989 to 1999 , more water tended to fall. The rainy season tended to start earlier and end later, thus being longer in length. In the second phase, after 1999, differences began to emerge by geographic region. The west coast area exhibited a steady downward trend, the East Sea region demonstrated a slightly decreasing trend, and little change or a slight increase was registered further inland.

Fifth, the impact of ENSO processes on precipitation was powerful. ORD, NRY, and LRS were particularly tightly related to ONI. The indicators for rainfall, that is, annual rainfall and dry season 
rainfall, were also correlated with ENSO processes, but with lower reliability. No correlation was found between NRW and ENSO processes, indicating that ENSO processes were not involved in droughts during the rainy season.

Author Contributions: V.H.D. developed the methodology and concept, performed data analysis, and structured and wrote the first draft; D.D.T. reviewed literature, edited the manuscript, and hydrographs and managed correspondence; H.T.N. and H.V.T. computed and contributed methods and concept; M.B.D. collected and analyzed data and wrote the draft; P.H.T. analyzed data and created maps; N.T.N. collected and analyzed data and testing; K.V.L., T.B.T.P., and A.H.N. revised the manuscript and data analysis; P.T.T.H. and D.D.C. reviewed the state-of-the-art and structured the manuscript. All authors have read and agreed to the published version of the manuscript.

Funding: This research received no external funding.

Acknowledgments: The authors thank Vietnam National University Ho Chi Minh City for funding the research at the KHCN-TNB/14-19/C23.

Conflicts of Interest: The authors declare no conflict of interest.

Data Availability: Data used for this study are available from the corresponding author upon request.

\section{Abbreviations}

VMD Vietnamese Mekong Delta

ENSO El Niño-Southern Oscillation

CMP Ca Mau Peninsula

LXQ Long Xuyen Quadrangle

ITCZ Inter Tropical Convergence Zone

ORD The date of onset of the rainy season

CRD The cessation date of the rainy season

LRS The length of the rainy season

VRY Total volume of rain that falls in a year

VRD The volume of rainfall in the dry season

NRY Number of consecutive days without rain in a year

NRW Number of consecutive days without rain in the rainy season

M-K Mann-Kendall

ONI Oceanic Niño Index

CFC Climate Prediction Center

$\mathrm{CV}$ Coefficient of variation

Cs Coefficient of skewness 


\section{Appendix A}

Table A1. Characteristics of the date of onset of the rainy season, ORD, the cessation date of the rainy season (CRD), and the length of the rainy season (LRS) at different probability levels.

\begin{tabular}{|c|c|c|c|c|c|c|c|c|c|c|}
\hline \multirow{2}{*}{ No. } & \multirow{2}{*}{ Location } & \multicolumn{3}{|c|}{ ORD } & \multicolumn{3}{|c|}{ CRD } & \multicolumn{3}{|c|}{ LRS } \\
\hline & & $25 \%$ & $50 \%$ & $75 \%$ & $25 \%$ & $50 \%$ & $75 \%$ & $25 \%$ & $50 \%$ & $75 \%$ \\
\hline 1 & Tien Giang & 29 April & 13 May & 28 May & 17 November & 4 November & 23 October & 198 & 176 & 156 \\
\hline 2 & Ben Tre & 29 April & 11 May & 23 May & 14 November & 1 November & 21 October & 194 & 174 & 158 \\
\hline 3 & Tra Vinh & 27 April & 7 May & 18 May & 14 November & 2 November & 22 October & 195 & 175 & 161 \\
\hline 4 & Soc Trang & 26 April & 6 May & 17 May & 20 November & 7 November & 26 October & 200 & 183 & 168 \\
\hline 5 & Bạc Lieu & 22 April & 3 May & 15 May & 28 November & 15 November & 2 November & 212 & 194 & 178 \\
\hline 6 & Ca Mau & 19 April & 30 April & 11 May & 30 November & 18 November & 6 November & 219 & 201 & 185 \\
\hline 7 & Kien Giang & 16 April & 28 April & 11 May & 29 November & 17 November & 5 November & 222 & 201 & 183 \\
\hline 8 & The estuaries & 28 April & 10 May & 23 May & 15 November & 2 November & 22 October & 196 & 175 & 158 \\
\hline 9 & Ca Mau Peninsula & 20 April & 1 May & 12 May & 27 November & 15 November & 3 November & 214 & 196 & 180 \\
\hline 10 & Long Xuyen Quadrangle & 17 April & 30 April & 14 May & 30 November & 17 November & 5 November & 219 & 199 & 179 \\
\hline 11 & Whole area & 22 April & 4 May & 16 May & 24 November & 11 November & 30 October & 209 & 190 & 173 \\
\hline
\end{tabular}


Table A2. Results of trend test of various rainfall characteristics for different periods.

\begin{tabular}{|c|c|c|c|c|c|c|c|c|c|c|c|c|}
\hline \multirow{2}{*}{ Period } & \multirow{2}{*}{ Values } & \multicolumn{7}{|c|}{ Province } & \multicolumn{3}{|c|}{ Subregion } & \multirow{2}{*}{$\begin{array}{l}\text { Whole } \\
\text { Area }\end{array}$} \\
\hline & & Tien Giang & Ben Tre & Tra Vinh & Soc Trang & Bac Lieu & Ca Mau & Kien Giang & The Estuaries & CMP & LXQ & \\
\hline \multicolumn{13}{|c|}{ Trend test of ORD } \\
\hline \multirow{8}{*}{ 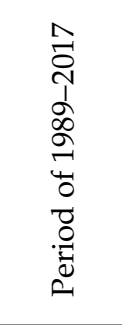 } & No. of year & 29 & 29 & 29 & 29 & 29 & 29 & 29 & 29 & 29 & 29 & 29 \\
\hline & Max & 164 & 155 & 147 & 145 & 142 & 141 & 142 & 153 & 139 & 151 & 145 \\
\hline & Min & 95 & 96 & 99 & 99 & 93 & 90 & 91 & 96 & 92 & 94 & 94 \\
\hline & $\mathrm{TB}$ & 135 & 133 & 130 & 129 & 126 & 122 & 120 & 133 & 123 & 123 & 126 \\
\hline & SD & 15 & 14 & 11 & 11 & 11 & 11 & 11 & 13 & 10 & 12 & 11 \\
\hline & $\mathrm{Zs}$ & -0.68 & -0.53 & -1.35 & -0.86 & -0.64 & -0.45 & -0.23 & -0.94 & -0.68 & -0.19 & -0.75 \\
\hline & $P$ value & 0.25 & 0.30 & 0.09 & 0.19 & 0.26 & 0.33 & 0.41 & 0.17 & 0.25 & 0.43 & 0.23 \\
\hline & Sen's slope & -0.48 & -0.31 & -0.41 & -0.37 & -0.10 & -0.08 & -0.05 & -0.40 & -0.18 & -0.18 & -0.26 \\
\hline \multirow{8}{*}{ 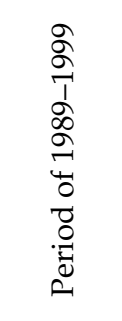 } & No. of year & 11 & 11 & 11 & 11 & 11 & 11 & 11 & 11 & 11 & 11 & 11 \\
\hline & $\operatorname{Max}$ & 164 & 155 & 144 & 144 & 142 & 141 & 133 & 153 & 136 & 139 & 141 \\
\hline & Min & 95 & 96 & 99 & 99 & 93 & 90 & 91 & 96 & 92 & 94 & 94 \\
\hline & $\mathrm{TB}$ & 141 & 137 & 134 & 133 & 127 & 123 & 121 & 137 & 125 & 124 & 129 \\
\hline & SD & 18 & 16 & 12 & 12 & 13 & 13 & 13 & 15 & 12 & 14 & 13 \\
\hline & Zs & -0.31 & -0.16 & -1.25 & 0.47 & -0.31 & 0.00 & -0.31 & -0.47 & 0.00 & 0.00 & -0.31 \\
\hline & $P$ value & 0.38 & 0.44 & 0.11 & 0.32 & 0.38 & 0.50 & 0.38 & 0.32 & 0.50 & 0.50 & 0.38 \\
\hline & Sen's slop & -0.30 & -0.35 & -1.11 & 0.38 & -0.38 & 0.17 & -0.29 & -0.44 & 0.04 & 0.34 & -0.34 \\
\hline \multirow{8}{*}{ 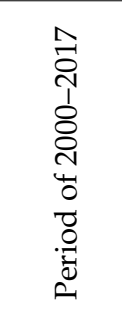 } & No. of year & 18 & 18 & 18 & 18 & 18 & 18 & 18 & 18 & 18 & 18 & 18 \\
\hline & $\operatorname{Max}$ & 156 & 155 & 147 & 145 & 141 & 138 & 142 & 152 & 139 & 151 & 145 \\
\hline & Min & 112 & 113 & 114 & 111 & 105 & 102 & 104 & 113 & 105 & 104 & 107 \\
\hline & $\mathrm{TB}$ & 132 & 130 & 128 & 126 & 125 & 121 & 119 & 130 & 122 & 122 & 124 \\
\hline & $\mathrm{SD}$ & 12 & 11 & 9 & 9 & 10 & 10 & 10 & 10 & 9 & 11 & 9 \\
\hline & $\mathrm{Zs}$ & 0.11 & 0.34 & 0.11 & 0.00 & 0.04 & 0.00 & 0.11 & 0.11 & -0.04 & 0.11 & 0.04 \\
\hline & $P$ value & 0.45 & 0.37 & 0.45 & 0.50 & 0.48 & 0.50 & 0.45 & 0.45 & 0.48 & 0.45 & 0.48 \\
\hline & Sen's slope & 0.55 & 0.60 & 0.60 & 0.25 & 0.63 & 0.29 & 0.24 & 0.53 & 0.43 & 0.16 & 0.39 \\
\hline
\end{tabular}


Table A2. Cont.

\begin{tabular}{|c|c|c|c|c|c|c|c|c|c|c|c|c|}
\hline \multirow{2}{*}{ Period } & \multirow{2}{*}{ Values } & \multicolumn{7}{|c|}{ Province } & \multicolumn{3}{|c|}{ Subregion } & \multirow{2}{*}{$\begin{array}{c}\text { Whole } \\
\text { Area }\end{array}$} \\
\hline & & Tien Giang & Ben Tre & Tra Vinh & Soc Trang & Bac Lieu & Ca Mau & Kien Giang & The Estuaries & CMP & LXQ & \\
\hline \multicolumn{13}{|c|}{ Trend test of CRD } \\
\hline \multirow{8}{*}{ 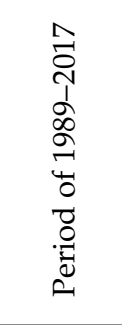 } & No. of year & 29 & 29 & 29 & 29 & 29 & 29 & 29 & 29 & 29 & 29 & 29 \\
\hline & $\operatorname{Max}$ & 343 & 334 & 330 & 336 & 345 & 351 & 342 & 336 & 344 & 350 & 341 \\
\hline & Min & 293 & 290 & 292 & 290 & 292 & 300 & 296 & 292 & 300 & 295 & 300 \\
\hline & $\mathrm{TB}$ & 310 & 308 & 309 & 313 & 320 & 323 & 322 & 309 & 320 & 322 & 317 \\
\hline & SD & 14 & 12 & 10 & 11 & 13 & 13 & 13 & 11 & 11 & 14 & 11 \\
\hline & Zs & 0.34 & 0.00 & 0.60 & 0.26 & 0.41 & 0.49 & 0.64 & 0.19 & 0.26 & 0.56 & 0.38 \\
\hline & $P$ value & 0.37 & 0.50 & 0.27 & 0.40 & 0.34 & 0.31 & 0.26 & 0.43 & 0.40 & 0.29 & 0.35 \\
\hline & Sen's slope & 0.21 & 0.00 & 0.19 & 0.09 & 0.21 & 0.59 & 0.40 & 0.12 & 0.31 & 0.60 & 0.23 \\
\hline \multirow{8}{*}{ 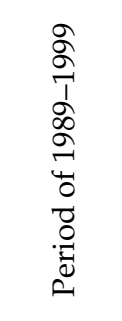 } & No. of year & 11 & 11 & 11 & 11 & 11 & 11 & 11 & 11 & 11 & 11 & 11 \\
\hline & $\operatorname{Max}$ & 339 & 334 & 327 & 332 & 343 & 345 & 337 & 328 & 338 & 339 & 333 \\
\hline & Min & 293 & 292 & 296 & 307 & 305 & 300 & 303 & 296 & 306 & 298 & 305 \\
\hline & $\mathrm{TB}$ & 310 & 310 & 309 & 314 & 320 & 321 & 320 & 309 & 319 & 319 & 316 \\
\hline & SD & 14 & 12 & 9 & 8 & 13 & 14 & 11 & 11 & 11 & 12 & 10 \\
\hline & Zs & 2.49 & 2.34 & 1.87 & 2.49 & 1.56 & 1.87 & 2.65 & 2.34 & 1.87 & 2.65 & 2.18 \\
\hline & $P$ value & 0.01 & 0.01 & 0.03 & 0.01 & 0.06 & 0.03 & 0.00 & 0.01 & 0.03 & 0.00 & 0.01 \\
\hline & Sen's slope & 3.31 & 3.04 & 1.82 & 1.02 & 3.25 & 3.20 & 3.05 & 2.73 & 2.81 & 3.04 & 2.48 \\
\hline \multirow{8}{*}{ 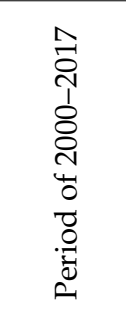 } & No. of year & 18 & 18 & 18 & 18 & 18 & 18 & 18 & 18 & 18 & 18 & 18 \\
\hline & $\operatorname{Max}$ & 343 & 333 & 330 & 336 & 345 & 351 & 342 & 336 & 344 & 350 & 341 \\
\hline & Min & 293 & 290 & 292 & 290 & 292 & 302 & 296 & 292 & 300 & 295 & 300 \\
\hline & $\mathrm{TB}$ & 311 & 308 & 309 & 313 & 320 & 325 & 323 & 309 & 321 & 323 & 318 \\
\hline & SD & 14 & 12 & 10 & 13 & 13 & 12 & 13 & 12 & 11 & 15 & 11 \\
\hline & Zs & -0.19 & -0.42 & 0.27 & -0.19 & -0.11 & -0.04 & -0.27 & -0.27 & -0.27 & -0.11 & -0.19 \\
\hline & $P$ value & 0.42 & 0.34 & 0.40 & 0.42 & 0.45 & 0.48 & 0.40 & 0.40 & 0.40 & 0.45 & 0.42 \\
\hline & Sen's slope & 0.04 & -0.30 & 0.34 & -0.24 & 0.11 & 0.82 & 0.38 & -0.12 & 0.39 & 0.64 & 0.24 \\
\hline
\end{tabular}


Table A2. Cont.

\begin{tabular}{|c|c|c|c|c|c|c|c|c|c|c|c|c|}
\hline \multirow{2}{*}{ Period } & \multirow{2}{*}{ Values } & \multicolumn{7}{|c|}{ Province } & \multicolumn{3}{|c|}{ Subregion } & \multirow{2}{*}{$\begin{array}{c}\text { Whole } \\
\text { Area }\end{array}$} \\
\hline & & Tien Giang & Ben Tre & Tra Vinh & Soc Trang & Bac Lieu & Ca Mau & Kien Giang & The Estuaries & CMP & LXQ & \\
\hline \multicolumn{13}{|c|}{ Trend test of LRS } \\
\hline \multirow{8}{*}{ 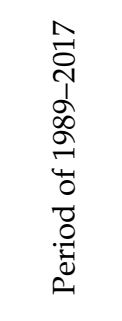 } & No. of year & 29 & 29 & 29 & 29 & 29 & 29 & 29 & 29 & 29 & 29 & 29 \\
\hline & Max & 232 & 224 & 223 & 231 & 245 & 255 & 241 & 227 & 245 & 242 & 239 \\
\hline & Min & 133 & 139 & 156 & 155 & 171 & 174 & 176 & 146 & 174 & 165 & 167 \\
\hline & $\mathrm{TB}$ & 175 & 176 & 179 & 185 & 194 & 202 & 202 & 177 & 197 & 199 & 191 \\
\hline & SD & 20 & 19 & 15 & 16 & 16 & 17 & 18 & 17 & 16 & 20 & 16 \\
\hline & Zs & 0.94 & 0.64 & 1.43 & 0.71 & 0.64 & 0.60 & 0.94 & 1.09 & 0.90 & 0.56 & 0.94 \\
\hline & $P$ value & 0.17 & 0.26 & 0.08 & 0.24 & 0.26 & 0.27 & 0.17 & 0.14 & 0.18 & 0.29 & 0.17 \\
\hline & Sen's slope & 0.71 & 0.34 & 0.60 & 0.55 & 0.28 & 0.73 & 0.80 & 0.58 & 0.66 & 0.79 & 0.69 \\
\hline \multirow{8}{*}{ 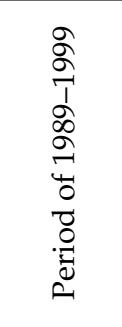 } & No. of year & 11 & 11 & 11 & 11 & 11 & 11 & 11 & 11 & 11 & 11 & 11 \\
\hline & $\operatorname{Max}$ & 232 & 224 & 223 & 231 & 245 & 255 & 241 & 227 & 245 & 239 & 239 \\
\hline & Min & 133 & 139 & 156 & 167 & 171 & 174 & 176 & 146 & 179 & 165 & 169 \\
\hline & $\mathrm{TB}$ & 169 & 173 & 175 & 181 & 193 & 197 & 198 & 173 & 194 & 195 & 187 \\
\hline & SD & 25 & 22 & 19 & 18 & 21 & 23 & 20 & 21 & 20 & 21 & 20 \\
\hline & Zs & 2.02 & 1.25 & 2.18 & 0.62 & 1.40 & 0.78 & 2.34 & 2.34 & 0.93 & 1.40 & 1.56 \\
\hline & $P$ value & 0.02 & 0.11 & 0.01 & 0.27 & 0.08 & 0.22 & 0.01 & 0.01 & 0.18 & 0.08 & 0.06 \\
\hline & Sen's slope & 3.59 & 3.45 & 2.60 & 0.62 & 3.41 & 1.75 & 4.01 & 3.54 & 1.33 & 2.89 & 2.34 \\
\hline \multirow{8}{*}{ 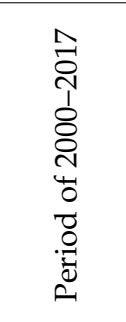 } & No. of year & 18 & 18 & 18 & 18 & 18 & 18 & 18 & 18 & 18 & 18 & 18 \\
\hline & Max & 209 & 213 & 206 & 222 & 218 & 227 & 238 & 208 & 225 & 242 & 222 \\
\hline & Min & 155 & 144 & 160 & 155 & 171 & 181 & 176 & 153 & 174 & 169 & 167 \\
\hline & TB & 179 & 177 & 181 & 187 & 195 & 204 & 204 & 179 & 199 & 201 & 193 \\
\hline & SD & 15 & 16 & 11 & 15 & 12 & 12 & 16 & 14 & 12 & 19 & 12 \\
\hline & Zs & -0.11 & -0.27 & 0.00 & -0.11 & -0.34 & -0.27 & -0.04 & -0.19 & -0.19 & -0.27 & -0.19 \\
\hline & $P$ value & 0.45 & 0.40 & 0.50 & 0.45 & 0.37 & 0.40 & 0.48 & 0.42 & 0.42 & 0.40 & 0.42 \\
\hline & Sen's slope & -0.13 & -0.32 & -0.30 & -0.25 & -0.72 & 0.23 & 0.80 & -0.26 & 0.45 & 0.74 & 0.39 \\
\hline
\end{tabular}


Table A2. Cont.

\begin{tabular}{|c|c|c|c|c|c|c|c|c|c|c|c|c|}
\hline \multirow{2}{*}{ Period } & \multirow{2}{*}{ Values } & \multicolumn{7}{|c|}{ Province } & \multicolumn{3}{|c|}{ Subregion } & \multirow{2}{*}{$\begin{array}{c}\text { Whole } \\
\text { Area }\end{array}$} \\
\hline & & Tien Giang & Ben Tre & Tra Vinh & Soc Trang & Bac Lieu & Ca Mau & Kien Giang & The Estuaries & CMP & LXQ & \\
\hline \multicolumn{13}{|c|}{ Trend test of annual rainfall } \\
\hline \multirow{8}{*}{  } & No. of year & 29 & 29 & 29 & 29 & 29 & 29 & 29 & 29 & 29 & 29 & 29 \\
\hline & Max & 1835 & 1858 & 2108 & 2339 & 2566 & 2906 & 2653 & 1915 & 2706 & 2538 & 2427 \\
\hline & Min & 1118 & 1159 & 1251 & 1290 & 1543 & 1908 & 1567 & 1197 & 1755 & 1443 & 1556 \\
\hline & $\mathrm{TB}$ & 1439 & 1485 & 1584 & 1716 & 1921 & 2247 & 2028 & 1507 & 2045 & 1923 & 1860 \\
\hline & SD & 192 & 182 & 199 & 214 & 245 & 232 & 234 & 177 & 214 & 257 & 196 \\
\hline & $\mathrm{Zs}$ & 0.68 & 0.41 & 0.56 & 1.01 & 1.46 & 0.94 & 0.94 & 0.68 & 1.13 & 0.90 & 1.13 \\
\hline & $P$ value & 0.25 & 0.34 & 0.29 & 0.16 & 0.07 & 0.17 & 0.17 & 0.25 & 0.13 & 0.18 & 0.13 \\
\hline & Sen's slope & 12.48 & 2.38 & -1.77 & -0.33 & 10.19 & 2.66 & -1.25 & 4.15 & 2.94 & -3.55 & 2.13 \\
\hline \multirow{8}{*}{ 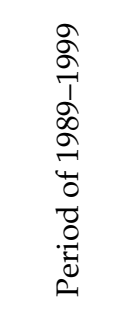 } & No. of year & 11 & 11 & 11 & 11 & 11 & 11 & 11 & 11 & 11 & 11 & 11 \\
\hline & $\operatorname{Max}$ & 1741 & 1856 & 2108 & 2339 & 2566 & 2906 & 2653 & 1915 & 2706 & 2538 & 2427 \\
\hline & Min & 1118 & 1164 & 1261 & 1466 & 1543 & 1947 & 1756 & 1209 & 1774 & 1560 & 1568 \\
\hline & $\mathrm{TB}$ & 1364 & 1470 & 1605 & 1738 & 1861 & 2236 & 2062 & 1487 & 2039 & 1958 & 1855 \\
\hline & SD & 181 & 195 & 201 & 227 & 289 & 252 & 269 & 186 & 249 & 286 & 226 \\
\hline & $\mathrm{Zs}$ & 2.34 & 1.87 & 1.71 & 2.18 & 2.96 & 3.11 & 2.49 & 2.02 & 2.96 & 2.18 & 2.96 \\
\hline & $P$ value & 0.01 & 0.03 & 0.04 & 0.01 & 0.00 & 0.00 & 0.01 & 0.02 & 0.00 & 0.01 & 0.00 \\
\hline & Sen's slope & 51.49 & 48.70 & 31.87 & 44.90 & 59.81 & 44.91 & 42.55 & 40.63 & 43.67 & 57.77 & 53.77 \\
\hline \multirow{8}{*}{ 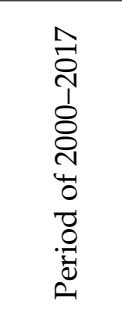 } & No. of year & 18 & 18 & 18 & 18 & 18 & 18 & 18 & 18 & 18 & 18 & 18 \\
\hline & $\operatorname{Max}$ & 1835 & 1858 & 1931 & 2084 & 2369 & 2810 & 2447 & 1846 & 2512 & 2483 & 2175 \\
\hline & Min & 1156 & 1159 & 1251 & 1290 & 1596 & 1908 & 1567 & 1197 & 1755 & 1443 & 1556 \\
\hline & $\mathrm{TB}$ & 1484 & 1494 & 1571 & 1702 & 1957 & 2254 & 2008 & 1520 & 2049 & 1902 & 1863 \\
\hline & SD & 185 & 174 & 196 & 204 & 206 & 219 & 207 & 170 & 190 & 235 & 175 \\
\hline & $\mathrm{Zs}$ & -0.11 & -0.19 & -0.04 & 0.04 & 0.27 & -0.11 & 0.00 & -0.19 & 0.00 & -0.04 & 0.00 \\
\hline & $P$ value & 0.45 & 0.42 & 0.48 & 0.48 & 0.40 & 0.45 & 0.50 & 0.42 & 0.50 & 0.48 & 0.50 \\
\hline & Sen's slope & 12.45 & -3.77 & -10.02 & -16.39 & -1.75 & -6.24 & -15.86 & -4.22 & -11.39 & -23.39 & -11.59 \\
\hline
\end{tabular}


Table A2. Cont.

\begin{tabular}{|c|c|c|c|c|c|c|c|c|c|c|c|c|}
\hline \multirow{2}{*}{ Period } & \multirow{2}{*}{ Values } & \multicolumn{7}{|c|}{ Province } & \multicolumn{3}{|c|}{ Subregion } & \multirow{2}{*}{$\begin{array}{c}\text { Whole } \\
\text { Area }\end{array}$} \\
\hline & & Tien Giang & Ben Tre & Tra Vinh & Soc Trang & Bac Lieu & Ca Mau & Kien Giang & The Estuaries & CMP & LXQ & \\
\hline \multicolumn{13}{|c|}{ Trend test of rainfall in the dry season } \\
\hline \multirow{8}{*}{ 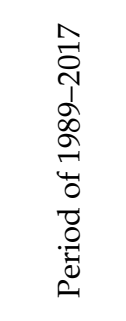 } & No. of year & 29 & 29 & 29 & 29 & 29 & 29 & 29 & 29 & 29 & 29 & 29 \\
\hline & $\operatorname{Max}$ & 285 & 264 & 265 & 371 & 456 & 501 & 512 & 273 & 482 & 440 & 411 \\
\hline & Min & 6 & 3 & 1 & 4 & 2 & 8 & 11 & 6 & 7 & 8 & 7 \\
\hline & $\mathrm{TB}$ & 66 & 57 & 62 & 81 & 105 & 136 & 156 & 62 & 123 & 144 & 107 \\
\hline & $\mathrm{SD}$ & 60 & 57 & 59 & 81 & 97 & 109 & 110 & 58 & 100 & 103 & 86 \\
\hline & Zs & 0.34 & 0.11 & 0.53 & 0.04 & -0.41 & -0.04 & 0.00 & 0.15 & 0.00 & 0.00 & -0.04 \\
\hline & $P$ value & 0.37 & 0.46 & 0.30 & 0.49 & 0.34 & 0.49 & 0.50 & 0.44 & 0.50 & 0.50 & 0.49 \\
\hline & Sen's slope & 1.69 & 0.88 & 0.60 & 0.91 & -0.37 & -0.14 & 0.30 & 1.16 & 0.36 & 1.56 & 0.99 \\
\hline \multirow{8}{*}{ 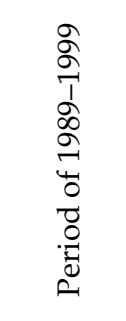 } & No. of year & 11 & 11 & 11 & 11 & 11 & 11 & 11 & 11 & 11 & 11 & 11 \\
\hline & $\operatorname{Max}$ & 285 & 264 & 265 & 371 & 456 & 501 & 512 & 273 & 482 & 440 & 411 \\
\hline & Min & 6 & 5 & 11 & 14 & 7 & 24 & 56 & 14 & 29 & 33 & 28 \\
\hline & $\mathrm{TB}$ & 60 & 52 & 50 & 71 & 111 & 136 & 156 & 54 & 124 & 137 & 104 \\
\hline & $\mathrm{SD}$ & 76 & 70 & 69 & 96 & 115 & 125 & 126 & 71 & 119 & 110 & 102 \\
\hline & Zs & 1.09 & 0.62 & 0.93 & 0.16 & -0.78 & 0.16 & 0.93 & 0.62 & 0.16 & 0.78 & 0.31 \\
\hline & $P$ value & 0.14 & 0.27 & 0.18 & 0.44 & 0.22 & 0.44 & 0.18 & 0.27 & 0.44 & 0.22 & 0.38 \\
\hline & Sen's slope & 5.66 & 2.42 & 1.09 & 0.05 & -7.63 & 2.96 & 12.22 & 2.84 & 2.60 & 10.98 & 2.08 \\
\hline \multirow{8}{*}{ 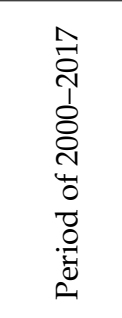 } & No. of year & 18 & 18 & 18 & 18 & 18 & 18 & 18 & 18 & 18 & 18 & 18 \\
\hline & $\operatorname{Max}$ & 153 & 165 & 166 & 253 & 276 & 301 & 330 & 165 & 271 & 342 & 242 \\
\hline & Min & 7 & 3 & 1 & 4 & 2 & 8 & 11 & 6 & 7 & 8 & 7 \\
\hline & TB & 71 & 60 & 70 & 87 & 102 & 137 & 155 & 67 & 123 & 149 & 109 \\
\hline & SD & 47 & 47 & 52 & 71 & 85 & 98 & 99 & 47 & 87 & 98 & 74 \\
\hline & Zs & -0.11 & -0.04 & -0.27 & -0.04 & -0.19 & -0.11 & -0.27 & -0.04 & -0.04 & -0.19 & -0.11 \\
\hline & $P$ value & 0.45 & 0.48 & 0.40 & 0.48 & 0.42 & 0.45 & 0.40 & 0.48 & 0.48 & 0.42 & 0.45 \\
\hline & Sen's slope & 1.60 & -0.42 & -0.99 & -0.34 & -0.28 & -1.97 & -2.79 & 0.07 & -1.11 & -1.20 & -1.02 \\
\hline
\end{tabular}


Table A2. Cont.

\begin{tabular}{|c|c|c|c|c|c|c|c|c|c|c|c|c|}
\hline \multirow{2}{*}{ Period } & \multirow{2}{*}{ Values } & \multicolumn{7}{|c|}{ Province } & \multicolumn{3}{|c|}{ Subregion } & \multirow{2}{*}{$\begin{array}{c}\text { Whole } \\
\text { Area }\end{array}$} \\
\hline & & Tien Giang & Ben Tre & Tra Vinh & Soc Trang & Bac Lieu & Ca Mau & Kien Giang & The Estuaries & CMP & LXQ & \\
\hline \multicolumn{13}{|c|}{ Trend test of rainfall in the dry season } \\
\hline \multirow{8}{*}{ 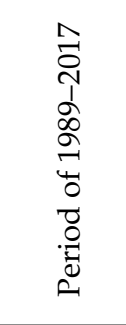 } & No. of year & 29 & 29 & 29 & 29 & 29 & 29 & 29 & 29 & 29 & 29 & 29 \\
\hline & $\operatorname{Max}$ & 172 & 181 & 167 & 168 & 174 & 142 & 141 & 173 & 152 & 144 & 152 \\
\hline & Min & 55 & 65 & 52 & 65 & 58 & 41 & 41 & 63 & 53 & 41 & 56 \\
\hline & $\mathrm{TB}$ & 112 & 121 & 120 & 114 & 104 & 91 & 85 & 117 & 98 & 86 & 103 \\
\hline & $\mathrm{SD}$ & 35 & 32 & 28 & 28 & 31 & 32 & 28 & 31 & 30 & 29 & 29 \\
\hline & Zs & -0.49 & -0.38 & -0.56 & -0.56 & -0.26 & -0.38 & -0.23 & -0.45 & -0.45 & 0.00 & -0.38 \\
\hline & $P$ value & 0.31 & 0.35 & 0.29 & 0.29 & 0.40 & 0.35 & 0.41 & 0.33 & 0.33 & 0.50 & 0.35 \\
\hline & Sen's slope & -1.01 & -0.96 & -0.94 & -0.54 & -0.43 & -0.83 & -0.26 & -1.00 & -0.70 & -0.39 & -0.76 \\
\hline \multirow{8}{*}{ 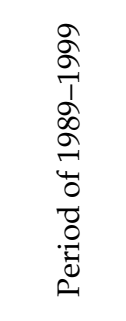 } & No. of year & 11 & 11 & 11 & 11 & 11 & 11 & 11 & 11 & 11 & 11 & 11 \\
\hline & $\operatorname{Max}$ & 172 & 181 & 167 & 168 & 174 & 142 & 127 & 173 & 152 & 126 & 152 \\
\hline & Min & 55 & 79 & 92 & 72 & 68 & 41 & 43 & 76 & 53 & 45 & 59 \\
\hline & $\mathrm{TB}$ & 123 & 129 & 128 & 122 & 111 & 96 & 88 & 127 & 104 & 90 & 109 \\
\hline & $\mathrm{SD}$ & 36 & 35 & 27 & 27 & 29 & 29 & 24 & 32 & 27 & 25 & 27 \\
\hline & Zs & -1.09 & -0.78 & -1.09 & -0.31 & 0.00 & -0.78 & -0.62 & -1.09 & -0.93 & -0.16 & -0.62 \\
\hline & $P$ value & 0.14 & 0.22 & 0.14 & 0.38 & 0.50 & 0.22 & 0.27 & 0.14 & 0.18 & 0.44 & 0.27 \\
\hline & Sen's slope & -5.93 & -4.44 & -4.61 & -3.24 & 0.17 & -3.64 & -3.74 & -5.47 & -4.83 & -1.94 & -4.91 \\
\hline \multirow{8}{*}{ 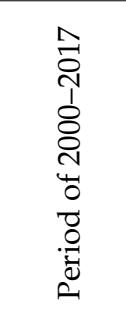 } & No. of year & 18 & 18 & 18 & 18 & 18 & 18 & 18 & 18 & 18 & 18 & 18 \\
\hline & $\operatorname{Max}$ & 165 & 162 & 152 & 159 & 151 & 140 & 141 & 157 & 146 & 144 & 147 \\
\hline & Min & 70 & 65 & 52 & 65 & 58 & 46 & 41 & 63 & 54 & 41 & 56 \\
\hline & TB & 104 & 116 & 114 & 109 & 100 & 89 & 83 & 112 & 95 & 84 & 99 \\
\hline & SD & 32 & 29 & 28 & 28 & 32 & 33 & 30 & 28 & 31 & 31 & 29 \\
\hline & Zs & 0.04 & 0.04 & 0.11 & -0.04 & -0.04 & 0.00 & 0.19 & 0.11 & 0.00 & 0.19 & 0.04 \\
\hline & $P$ value & 0.48 & 0.48 & 0.45 & 0.48 & 0.48 & 0.50 & 0.42 & 0.45 & 0.50 & 0.42 & 0.48 \\
\hline & Sen's slope & 0.75 & -0.50 & -0.26 & 0.73 & -0.20 & -0.52 & 1.07 & -0.07 & 0.11 & 0.25 & 0.29 \\
\hline
\end{tabular}


Table A2. Cont.

\begin{tabular}{|c|c|c|c|c|c|c|c|c|c|c|c|c|}
\hline \multirow{2}{*}{ Period } & \multirow{2}{*}{ Values } & \multicolumn{7}{|c|}{ Province } & \multicolumn{3}{|c|}{ Subregion } & \multirow{2}{*}{$\begin{array}{c}\text { Whole } \\
\text { Area }\end{array}$} \\
\hline & & Tien Giang & Ben Tre & Tra Vinh & Soc Trang & Bac Lieu & Ca Mau & Kien Giang & The Estuaries & CMP & LXQ & \\
\hline \multicolumn{13}{|c|}{ Test the trend of the longest consecutive days without rain in the rainy season } \\
\hline \multirow{8}{*}{ 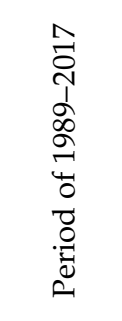 } & No. of year & 29 & 29 & 29 & 29 & 29 & 29 & 29 & 29 & 29 & 29 & 29 \\
\hline & Max & 19 & 20 & 21 & 21 & 24 & 22 & 23 & 18 & 21 & 19 & 19 \\
\hline & Min & 12 & 11 & 10 & 10 & 9 & 11 & 11 & 11 & 11 & 11 & 12 \\
\hline & $\mathrm{TB}$ & 15 & 15 & 14 & 14 & 14 & 14 & 14 & 15 & 14 & 14 & 14 \\
\hline & SD & 2 & 2 & 2 & 3 & 3 & 2 & 2 & 2 & 2 & 2 & 2 \\
\hline & $\mathrm{Zs}$ & -0.41 & -0.08 & 0.30 & 0.00 & 0.04 & -0.64 & 0.41 & -0.19 & -0.41 & 0.56 & -0.23 \\
\hline & $P$ value & 0.34 & 0.47 & 0.38 & 0.50 & 0.49 & 0.26 & 0.34 & 0.43 & 0.34 & 0.29 & 0.41 \\
\hline & Sen's slope & -0.09 & 0.01 & 0.02 & -0.01 & -0.04 & -0.06 & 0.03 & -0.03 & -0.05 & 0.06 & -0.03 \\
\hline \multirow{8}{*}{ 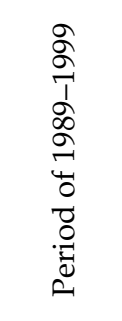 } & No. of year & 11 & 11 & 11 & 11 & 11 & 11 & 11 & 11 & 11 & 11 & 11 \\
\hline & $\operatorname{Max}$ & 19 & 20 & 18 & 17 & 24 & 22 & 23 & 18 & 21 & 19 & 19 \\
\hline & Min & 12 & 11 & 10 & 10 & 10 & 11 & 11 & 11 & 12 & 11 & 12 \\
\hline & $\mathrm{TB}$ & 16 & 15 & 14 & 14 & 14 & 14 & 14 & 15 & 14 & 14 & 14 \\
\hline & SD & 2 & 3 & 3 & 3 & 3 & 3 & 3 & 2 & 2 & 2 & 2 \\
\hline & Zs & 0.47 & 0.00 & 0.00 & -0.16 & 0.00 & -0.62 & 1.09 & -0.31 & -0.31 & 0.31 & -0.16 \\
\hline & $P$ value & 0.32 & 0.50 & 0.50 & 0.44 & 0.50 & 0.27 & 0.14 & 0.38 & 0.38 & 0.38 & 0.44 \\
\hline & Sen's slope & 0.07 & -0.01 & -0.01 & -0.02 & 0.01 & -0.15 & 0.20 & -0.09 & -0.07 & 0.08 & -0.08 \\
\hline \multirow{8}{*}{ 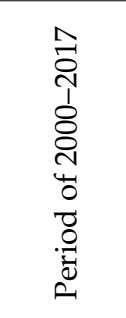 } & No. of year & 18 & 18 & 18 & 18 & 18 & 18 & 18 & 18 & 18 & 18 & 18 \\
\hline & $\operatorname{Max}$ & 16 & 18 & 21 & 21 & 24 & 17 & 15 & 17 & 17 & 16 & 17 \\
\hline & Min & 12 & 13 & 11 & 11 & 9 & 11 & 12 & 12 & 11 & 11 & 12 \\
\hline & $\mathrm{TB}$ & 15 & 15 & 14 & 14 & 14 & 13 & 13 & 15 & 14 & 14 & 14 \\
\hline & SD & 1 & 2 & 2 & 3 & 3 & 2 & 1 & 1 & 2 & 1 & 1 \\
\hline & Zs & -0.34 & -0.19 & 0.11 & -0.11 & -0.57 & -0.42 & 0.34 & -0.27 & -0.57 & 0.42 & -0.42 \\
\hline & $P$ value & 0.37 & 0.42 & 0.45 & 0.45 & 0.28 & 0.34 & 0.37 & 0.40 & 0.28 & 0.34 & 0.34 \\
\hline & Sen's slope & -0.08 & -0.02 & -0.07 & -0.04 & -0.23 & -0.09 & 0.07 & -0.06 & -0.12 & 0.10 & -0.04 \\
\hline
\end{tabular}


Table A3. Results of trend test of rainfall characteristics at four rain stations for different periods.

\begin{tabular}{|c|c|c|c|c|c|}
\hline & Characteristics & Rach Gia & Ca Mau & Soc Trang & My Tho \\
\hline \multirow{8}{*}{ 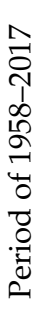 } & No. of year & 59 (1958) & 59 (1958) & 44 (1974) & 40 (1978) \\
\hline & Max & 3085 & 3549 & 2754 & 1884 \\
\hline & Min & 1529 & 1932 & 1395 & 758 \\
\hline & $\mathrm{TB}$ & 2150 & 2390 & 1907 & 1434 \\
\hline & SD & 343 & 297 & 288 & 257 \\
\hline & $\mathrm{Zs}$ & 1.04 & 0.11 & -0.07 & 2.69 \\
\hline & $P$ value & 0.15 & 0.46 & 0.47 & 0.004 \\
\hline & Sen's slope & 3.48 & -2.60 & -0.26 & 7.96 \\
\hline \multirow{8}{*}{ 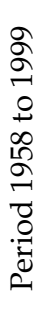 } & No. of year & 14 (1986) & 19 (1981) & 13 (1987) & $22(1978)$ \\
\hline & $\operatorname{Max}$ & 3085 & 3549 & 2754 & 1884 \\
\hline & Min & 2895 & 2299 & 2754 & 1211 \\
\hline & $\mathrm{TB}$ & 2178 & 2430 & 1920 & 1371 \\
\hline & SD & 410 & 346 & 342 & 261 \\
\hline & Zs & 1.31 & 2.66 & 2.38 & 2.20 \\
\hline & $P$ value & 0.09 & 0.00 & 0.01 & 0.01 \\
\hline & Sen's slope & 36.45 & 32.64 & 67.80 & 17.67 \\
\hline \multirow{8}{*}{ 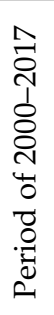 } & No. of year & 18 & 18 & 18 & 18 \\
\hline & Max & 2705 & 2630 & 2247 & 1818 \\
\hline & Min & 2510 & 2175 & 2247 & 1670 \\
\hline & ТВ & 2177 & 2287 & 1875 & 1511 \\
\hline & SD & 313 & 215 & 263 & 230 \\
\hline & $\mathrm{Zs}$ & -0.38 & -1.29 & -0.76 & 0.68 \\
\hline & $P$ value & 0.35 & 0.10 & 0.22 & 0.25 \\
\hline & Sen's slope & -9.10 & -16.71 & -19.62 & 6.12 \\
\hline
\end{tabular}


Table A4. Results of autocorrelation analysis for the rainfall data.

\begin{tabular}{|c|c|c|c|c|c|c|c|c|c|c|c|}
\hline \multirow{2}{*}{ No. } & \multirow{2}{*}{ Station/Region } & \multirow{2}{*}{ Duration } & \multirow{2}{*}{ No. of Year } & \multicolumn{4}{|c|}{ Lag-1 } & \multicolumn{4}{|c|}{ Lag-2 } \\
\hline & & & & AC & PC & Q-Start & Prob & AC & PC & Q-Start & Prob \\
\hline I & Annual rainfall & & & & & & & & & & \\
\hline 1.1 & Whole area & 1989-2017 & 29 & 0.296 & 0.296 & 2.8051 & 0.094 & 0.120 & 0.036 & 3.2849 & 0.194 \\
\hline 1.2 & LXQ & 1989-2017 & 29 & 0.236 & 0.236 & 1.7812 & 0.182 & 0.073 & 0.019 & 1.9604 & 0.375 \\
\hline 1.3 & $\mathrm{CMP}$ & 1989-2017 & 29 & 0.348 & 0.348 & 3.8915 & 0.049 & 0.156 & 0.039 & 4.6984 & 0.095 \\
\hline 1.4 & The estuary & 1989-2017 & 29 & 0.097 & 0.097 & 0.3014 & 0.583 & 0.033 & 0.023 & 0.3367 & 0.845 \\
\hline 1.5 & Tien Giang & 1989-2017 & 29 & 0.313 & 0.313 & 3.1362 & 0.077 & 0.056 & -0.046 & 3.2411 & 0.198 \\
\hline 1.6 & Ben Tre & 1989-2017 & 29 & 0.415 & 0.415 & 5.5404 & 0.019 & 0.067 & -0.127 & 5.6914 & 0.058 \\
\hline 1.7 & Tra Vinh & 1989-2017 & 29 & 0.254 & 0.254 & 2.0716 & 0.150 & 0.183 & 0.127 & 3.1872 & 0.203 \\
\hline 1.8 & Soc Trang & 1989-2017 & 29 & 0.161 & 0.161 & 0.8329 & 0.361 & 0.311 & 0.293 & 4.0609 & 0.131 \\
\hline 1.9 & Bạc Lieu & 1989-2017 & 29 & -0.013 & -0.013 & 0.0051 & 0.943 & 0.116 & 0.115 & 0.4498 & 0.799 \\
\hline 1.10 & Ca Mau & 1989-2017 & 29 & 0.085 & 0.085 & 0.2301 & 0.631 & 0.103 & 0.096 & 0.5831 & 0.747 \\
\hline 1.11 & Kien Giang & 1989-2017 & 29 & 0.286 & 0.286 & 2.6294 & 0.105 & 0.039 & -0.047 & 2.6795 & 0.262 \\
\hline II & ORD & & & & & & & & & & \\
\hline 2.1 & Whole area & 1989-2017 & 29 & 0.195 & 0.195 & 1.2170 & 0.270 & -0.174 & -0.220 & 2.2229 & 0.329 \\
\hline 2.2 & LXQ & 1989-2017 & 29 & 0.120 & 0.120 & 0.4646 & 0.495 & -0.169 & -0.186 & 1.4121 & 0.494 \\
\hline 2.3 & $\mathrm{CMP}$ & 1989-2017 & 29 & 0.189 & 0.189 & 1.1499 & 0.284 & -0.113 & -0.154 & 1.5744 & 0.455 \\
\hline 2.4 & The estuary & 1989-2017 & 29 & 0.202 & 0.202 & 1.3158 & 0.251 & -0.204 & -0.255 & 2.6973 & 0.260 \\
\hline 2.5 & Tien Giang & 1989-2017 & 29 & 0.154 & 0.154 & 0.7601 & 0.383 & -0.201 & -0.230 & 2.1100 & 0.348 \\
\hline 2.6 & Ben Tre & 1989-2017 & 29 & 0.190 & 0.190 & 1.1614 & 0.281 & -0.197 & -0.242 & 2.4573 & 0.293 \\
\hline 2.7 & Tra Vinh & 1989-2017 & 29 & 0.230 & 0.230 & 1.7005 & 0.192 & -0.159 & -0.224 & 2.5473 & 0.280 \\
\hline 2.8 & Soc Trang & 1989-2017 & 29 & 0.195 & 0.195 & 1.2223 & 0.269 & -0.121 & -0.165 & 1.7077 & 0.426 \\
\hline 2.9 & Bạc Lieu & 1989-2017 & 29 & 0.129 & 0.129 & 0.5337 & 0.465 & -0.100 & -0.119 & 0.8666 & 0.648 \\
\hline 2.10 & Ca Mau & 1989-2017 & 29 & 0.169 & 0.169 & 0.9119 & 0.340 & -0.180 & -0.215 & 1.9921 & 0.369 \\
\hline 2.11 & Kien Giang & 1989-2017 & 29 & 0.176 & 0.176 & 1.0001 & 0.317 & -0.141 & -0.178 & 1.6643 & 0.435 \\
\hline
\end{tabular}


Table A4. Cont.

\begin{tabular}{|c|c|c|c|c|c|c|c|c|c|c|c|}
\hline \multirow{2}{*}{ No. } & \multirow{2}{*}{ Station/Region } & \multirow{2}{*}{ Duration } & \multirow{2}{*}{ No. of Year } & \multicolumn{4}{|c|}{ Lag-1 } & \multicolumn{4}{|c|}{ Lag-2 } \\
\hline & & & & $\mathrm{AC}$ & PC & Q-Start & Prob & $\mathrm{AC}$ & PC & Q-Start & Prob \\
\hline III & CRD & & & & & & & & & & \\
\hline 3.1 & Whole area & 1989-2017 & 29 & -0.179 & -0.179 & 1.0286 & 0.310 & 0.065 & 0.034 & 1.1685 & 0.558 \\
\hline 3.2 & LXQ & 1989-2017 & 29 & -0.090 & -0.090 & 0.2616 & 0.609 & 0.146 & 0.139 & 0.9718 & 0.615 \\
\hline 3.3 & $\mathrm{CMP}$ & 1989-2017 & 29 & -0.217 & -0.217 & 1.5052 & 0.220 & -0.004 & -0.053 & 1.5056 & 0.471 \\
\hline 3.4 & The estuary & 1989-2017 & 29 & -0.074 & -0.074 & 0.1776 & 0.673 & 0.031 & 0.025 & 0.2093 & 0.901 \\
\hline 3.5 & Tien Giang & 1989-2017 & 29 & -0.081 & -0.081 & 0.2117 & 0.645 & 0.043 & 0.036 & 0.2728 & 0.872 \\
\hline 3.6 & Ben Tre & 1989-2017 & 29 & -0.004 & -0.004 & 0.0006 & 0.981 & 0.048 & 0.048 & 0.0770 & 0.962 \\
\hline 3.7 & Tra Vinh & 1989-2017 & 29 & -0.097 & -0.097 & 0.3045 & 0.581 & -0.092 & -0.103 & 0.5886 & 0.745 \\
\hline 3.8 & Soc Trang & 1989-2017 & 29 & -0.209 & -0.209 & 1.3970 & 0.237 & -0.136 & -0.188 & 2.0134 & 0.365 \\
\hline 3.9 & Bạc Lieu & 1989-2017 & 29 & -0.147 & -0.147 & 0.6972 & 0.404 & -0.175 & -0.201 & 1.7199 & 0.423 \\
\hline 3.10 & Ca Mau & 1989-2017 & 29 & -0.196 & -0.196 & 1.2326 & 0.267 & -0.012 & -0.053 & 1.2377 & 0.539 \\
\hline 3.11 & Kien Giang & 1989-2017 & 29 & -0.091 & -0.091 & 0.2634 & 0.608 & 0.184 & 0.177 & 1.3885 & 0.499 \\
\hline IV & LRS & & & & & & & & & & \\
\hline 4.1 & Whole area & 1989-2017 & 29 & 0.201 & 0.201 & 1.2989 & 0.254 & -0.027 & -0.070 & 1.3225 & 0.516 \\
\hline 4.2 & LXQ & 1989-2017 & 29 & 0.138 & 0.138 & 0.6110 & 0.434 & -0.114 & -0.136 & 1.0448 & 0.593 \\
\hline 4.3 & $\mathrm{CMP}$ & 1989-2017 & 29 & 0.165 & 0.165 & 0.8714 & 0.351 & -0.062 & -0.092 & 0.9991 & 0.607 \\
\hline 4.4 & The estuary & 1989-2017 & 29 & 0.236 & 0.236 & 1.7918 & 0.181 & 0.025 & -0.033 & 1.8124 & 0.404 \\
\hline 4.5 & Tien Giang & 1989-2017 & 29 & 0.282 & 0.282 & 2.5559 & 0.110 & 0.067 & -0.014 & 2.7034 & 0.259 \\
\hline 4.6 & Ben Tre & 1989-2017 & 29 & 0.253 & 0.253 & 2.0520 & 0.152 & -0.012 & -0.082 & 2.0571 & 0.358 \\
\hline 4.7 & Tra Vinh & 1989-2017 & 29 & 0.099 & 0.099 & 0.3157 & 0.574 & 0.003 & -0.007 & 0.3159 & 0.854 \\
\hline 4.8 & Soc Trang & 1989-2017 & 29 & 0.047 & 0.047 & 0.0720 & 0.788 & -0.130 & -0.132 & 0.6327 & 0.729 \\
\hline 4.9 & Bạc Lieu & 1989-2017 & 29 & 0.149 & 0.149 & 0.7136 & 0.398 & -0.025 & -0.049 & 0.7350 & 0.692 \\
\hline 4.10 & Ca Mau & 1989-2017 & 29 & 0.126 & 0.126 & 0.5101 & 0.475 & -0.076 & -0.093 & 0.7001 & 0.705 \\
\hline 4.11 & Kien Giang & 1989-2017 & 29 & 0.221 & 0.221 & 1.5618 & 0.211 & -0.037 & -0.090 & 1.6085 & 0.447 \\
\hline
\end{tabular}


Table A4. Cont.

\begin{tabular}{|c|c|c|c|c|c|c|c|c|c|c|c|}
\hline \multirow{2}{*}{ No. } & \multirow{2}{*}{ Station/Region } & \multirow{2}{*}{ Duration } & \multirow{2}{*}{ No. of Year } & \multicolumn{4}{|c|}{ Lag-1 } & \multicolumn{4}{|c|}{ Lag-2 } \\
\hline & & & & AC & PC & Q-Start & Prob & AC & PC & Q-Start & Prob \\
\hline V & \multicolumn{11}{|c|}{ The longest consecutive days without rain in the year } \\
\hline 5.1 & Whole area & 1989-2017 & 29 & -0.002 & -0.002 & 0.0002 & 0.990 & 0.024 & 0.024 & 0.0188 & 0.991 \\
\hline 5.2 & LXQ & 1989-2017 & 29 & -0.013 & -0.013 & 0.0054 & 0.942 & 0.047 & 0.047 & 0.0798 & 0.961 \\
\hline 5.3 & CNP & 1989-2017 & 29 & -0.039 & -0.039 & 0.0480 & 0.827 & -0.014 & -0.016 & 0.0549 & 0.973 \\
\hline 5.4 & The estuary & 1989-2017 & 29 & 0.022 & 0.022 & 0.0159 & 0.900 & 0.094 & 0.093 & 0.3088 & 0.857 \\
\hline 5.5 & Tien Giang & 1989-2017 & 29 & 0.142 & 0.142 & 0.6511 & 0.420 & 0.144 & 0.126 & 1.3399 & 0.512 \\
\hline 5.6 & Ben Tre & 1989-2017 & 29 & -0.039 & -0.039 & 0.0478 & 0.827 & -0.039 & -0.039 & 0.0478 & 0.827 \\
\hline 5.7 & Tra Vinh & 1989-2017 & 29 & -0.032 & -0.032 & 0.0330 & 0.856 & 0.045 & 0.044 & 0.1002 & 0.951 \\
\hline 5.8 & Soc Trang & 1989-2017 & 29 & -0.066 & -0.066 & 0.1416 & 0.707 & 0.112 & 0.108 & 0.5604 & 0.756 \\
\hline 5.9 & Bạc Lieu & 1989-2017 & 29 & -0.123 & -0.123 & 0.4888 & 0.484 & -0.114 & -0.131 & 0.9187 & 0.632 \\
\hline 5.10 & Ca Mau & 1989-2017 & 29 & 0.071 & 0.071 & 0.1632 & 0.686 & -0.035 & -0.040 & 0.2032 & 0.903 \\
\hline 5.11 & Kien Giang & 1989-2017 & 29 & -0.007 & -0.007 & 0.0017 & 0.967 & -0.017 & -0.017 & 0.0118 & 0.994 \\
\hline VI & \multicolumn{11}{|c|}{ Rainfall at the four rain stations } \\
\hline 6.1 & Rach Gia & 1958-2017 & 60 & -0.046 & -0.046 & 0.1320 & 0.716 & -0.063 & -0.065 & 0.3832 & 0.826 \\
\hline 6.2 & Ca Mau & 1958-2017 & 60 & 0.172 & 0.172 & 1.8699 & 0.171 & 0.044 & 0.015 & 1.9955 & 0.369 \\
\hline 6.3 & Soc Trang & 1974-2017 & 44 & 0.218 & 0.218 & 2.2357 & 0.135 & 0.220 & 0.181 & 4.5737 & 0.102 \\
\hline 6.4 & My Tho & 1978-2017 & 40 & -0.053 & -0.053 & 0.1218 & 0.727 & 0.178 & 0.176 & 1.5223 & 0.467 \\
\hline
\end{tabular}




\section{References}

1. Wang, B. LinHo Rainy Season of the Asian-Pacific Summer Monsoon. J. Clim. 2002, 15, 386-398. [CrossRef]

2. Mainuddin, M.; Kirby, M.; Hoanh, C.T. Impact of climate change on rainfed rice and options for adaptation in the lower Mekong Basin. Nat. Hazards 2013, 66, 905-938.

3. Jokisch, A.; Urban, W.; Kluge, T. Small Scale Rain- and Floodwater Harvesting for Horticulture in Central-Northern Namibia for Livelihood Improvement and as an Adaptation Strategy to Climate Change. In Implementing Climate Change Adaptation in Cities and Communities: Integrating Strategies and Educational Approaches; Leal Filho, W., Adamson, K., Dunk, R.M., Azeiteiro, U.M., Illingworth, S., Alves, F., Eds.; Springer International Publishing: Cham, Switzerland, 2016; pp. 39-52. ISBN 978-3-319-28591-7.

4. Wang, J.; Zhou, L.; Yang, X. Geographic Information Systems and Spatial Analysis for Coastal Ecosystem Research and Management; Springer: Berlin/Heidelberg, Germany, 2009; pp. 45-66.

5. McLusky, D.S.; Elliott, M. Life in Estuaries. In The Estuarine Ecosystem: Ecology, Threats and Management; Oxford University Press: Oxford, UK, 2004; pp. 19-33.

6. Dang, H.V.; Tran, D.D.; Pham, B.T.; Khoi, N.D.; Tran, H.P.; Nguyen, T.N. Exploring Freshwater Regimes and Impact Factors in the Coastal Estuaries of the Vietnamese Mekong Delta. Water 2019, 11, 782. [CrossRef]

7. Minderhoud, P.S.J.; Coumou, L.; Erban, L.E.; Middelkoop, H.; Stouthamer, E.; Addink, E.A. The relation between land use and subsidence in the Vietnamese Mekong delta. Sci. Total Environ. 2018, 634, 715-726. [CrossRef] [PubMed]

8. Temmerman, S.; Meire, P.; Bouma, T.J.; Herman, P.M.J.; Ysebaert, T.; De Vriend, H.J. Ecosystem-based coastal defence in the face of global change. Nature 2013, 504, 79-83. [CrossRef]

9. Minderhoud, P.S.J.; Erkens, G.; Pham, V.H.; Bui, V.T.; Erban, L.; Kooi, H.; Stouthamer, E. Impacts of 25 years of groundwater extraction on subsidence in the Mekong delta, Vietnam. Environ. Res. Lett. 2017, 12, 64006. [CrossRef]

10. Tosi, L.; Lio, C.D.; Strozzi, T.; Teatini, P. Combining L- and X-Band SAR Interferometry to Assess Ground Displacements in Heterogeneous Coastal Environments: The Po River Delta and Venice Lagoon, Italy. Remote Sens. 2016, 8, 308.

11. Ministry of Natural Resources and Environment of Vietnam. Scenarios of Climate Change and Sea Level Rise in Vietnam (In Vietnamese: Kịch bản biến đổi khí hậu và nước biển dâng cho Việt Nam); Vietnam Publishing House of Natural Resources-Environment and Cartography (NARENCA): Hanoi, Vietnam, 2016.

12. Han, M.; Nguyen, D.C. Hydrological Design of Multipurpose Micro-catchment Rainwater Management. Water Intell. Online 2018, 17. [CrossRef]

13. Hu, Y.; Xu, J.; Huang, Y.; Zhou, Y.; Pang, Y.; Shi, Z.; Chen, X. Spatial and Temporal Variations in the Rainy Season Onset over the Qinghai-Tibet Plateau. Water 2019, 11, 1960. [CrossRef]

14. Ngetich, K.F.; Mucheru-Muna, M.; Mugwe, J.N.; Shisanya, C.A.; Diels, J.; Mugendi, D.N. Length of growing season, rainfall temporal distribution, onset and cessation dates in the Kenyan highlands. Agric. For. Meteorol. 2014, 188, 24-32. [CrossRef]

15. Zhang, Y.; Li, T.; Wang, B.; Wu, G. Onset of the Summer Monsoon over the Indochina Peninsula: Climatology and Interannual Variations. J. Clim. 2002, 15, 3206-3221. [CrossRef]

16. Gobin, A.; Nguyen, H.T.; Pham, V.Q.; Pham, H.T.T. Heavy rainfall patterns in Vietnam and their relation with ENSO cycles. Int. J. Climatol. 2016, 36, 1686-1699. [CrossRef]

17. Ono, K.; Kazama, S.; Gunawardhana, L.N.; Kuraji, K. An investigation of extreme daily rainfall in the Mekong River Basin using a gridded precipitation dataset. Hydrol. Res. Lett. 2013, 7, 66-72. [CrossRef]

18. Ngu, N.D.; Hieu, N.T. Climate and Climate Resources of Vietnam (In Vietnamese: Khí hậu và tài nguyên khí hậu Việt Nam); Science and Technology: Hanoi, Vietnam, 2013.

19. Matsumoto, J. Seasonal transition of summer rainy season over indochina and adjacent monsoon region. Adv. Atmos. Sci. 1997, 14, 231-245. [CrossRef]

20. Tan, P.V.; Ha, P.T.; Quang, N.D.; Hiep, N.V.; Thanh, N.D. Changes in rainfall onset of rainy seasons in Highland area of the Southern Vietnam and forecasting ability (In Vietnamese: Sự biến đổi của ngày bắt đầu mùa mưa ở Tây nguyên và khả năng dự báo). VNU J. Sci. Sci. Environ. 2016, 32, 184-194.

21. Stern, R.D.; Dennett, M.D.; Garbutt, D.J. The start of the rains in West Africa. J. Climatol. 1981, 1, 59-68. [CrossRef] 
22. Dung, D.T.; van Halsema, G.; Hellegers, P.J.G.J.; Phi Hoang, L.; Quang Tran, T.; Kummu, M.; Ludwig, F. Assessing impacts of dike construction on the flood dynamics in the Mekong Delta. Hydrol. Earth Syst. Sci. 2018, 22, 1875-1896.

23. Ly, S.; Sohier, C.; Charles, C.; Degré, A. Different methods for spatial interpolation of rainfall data for operational hydrology and hydrological modeling at watershed scale: A review. Biotechnol. Agron. Soc. Environ. 2013, 17, 392-406.

24. Noori, M.J.; Hassan, H.H.; Mustafa, Y.T. Spatial Estimation of Rainfall Distribution and Its Classification in Duhok Governorate Using GIS. J. Water Resour. Prot. 2014, 06, 75-82. [CrossRef]

25. Hartkamp, A.D.; de Beurs, K.; Stein, A.; White, J. Interpolation Techniques for Climate Variables. Geographic Information Systems Series 99-01; CIMMYT: Mexico City, Mexico, 1999.

26. Thanh, N.D.; Tan, P. Van Non-parametric testing of the changing trends of the key meteorological factors for the period 1961-2007 (In Vietnamese: Kiểm nghiệm phi tham số xu thế biến đổi của một số yếu tố khí tượng cho giai đoạn 1961-2007). VNU J. Sci. Nat. Sci. Technol. 2012, 3S, 129-135.

27. Kendall, M.G. A New Measure of Rank Correlation. Biometrika 1938, 30, 81-93. [CrossRef]

28. Mann, H.B. Nonparametric Tests Against Trend. Econometrica 1945, 13, 245. [CrossRef]

29. Yue, S.; Pilon, P.; Cavadias, G. Power of the Mann-Kendall and Spearman's rho tests for detecting monotonic trends in hydrological series. J. Hydrol. 2002, 259, 254-271. [CrossRef]

30. Yue, S.; Wang, C. The Mann-Kendall Test Modified by Effective Sample Size to Detect Trend in Serially Correlated Hydrological Series. Water Resour. Manag. 2004, 18, 201-218. [CrossRef]

31. Shahid, S. Rainfall variability and the trends of wet and dry periods in Bangladesh. Int. J. Climatol. 2010, 30, 2299-2313. [CrossRef]

32. Sen, P.K. Estimates of the Regression Coefficient Based on Kendall's Tau. J. Am. Stat. Assoc. 1968, 63, 1379-1389. [CrossRef]

33. Piyoosh, A.K.; Ghosh, S.K. Effect of autocorrelation on temporal trends in rainfall in a valley region at the foothills of Indian Himalayas. Stoch. Environ. Res. Risk Assess. 2017, 31, 2075-2096. [CrossRef]

34. Serinaldi, F.; Kilsby, C.G. The importance of prewhitening in change point analysis under persistence. Stoch. Environ. Res. Risk Assess. 2016, 30, 763-777. [CrossRef]

35. Shrestha, M.B.; Bhatta, G.R. Selecting appropriate methodological framework for time series data analysis. J. Financ. Data Sci. 2018, 4, 71-89. [CrossRef]

36. Quyen, N.H. Study on Application of ARIMA Model in Forecasting Winter-Spring Seasonal Rainfall in Typical Provinces of Northern Delta of Vietnam (In Vietnamese: Nghiên cứu ứng dụng mô hình ARIMA để dụ báo lượng mưa vu Đông Xuân ở một số tỉnh vùng Đồng bằng Bắc bộ); University of Natural Sciences: Chi Minh City, Vietnam, 2013.

37. Khoi, D.N.; Trang, H.T. Analysis of Changes in Precipitation and Extremes Events in Ho Chi Minh City, Vietnam. Procedia Eng. 2016, 142, 229-235. [CrossRef]

38. Hieu, N.T. Study on Basic Characteristics and Impacts of ENSO on the Droughts, Extreme Events in Vietnam and Forecasting Ability (In Vietnamese: Nghiên cứu nhũng đặc trưng cơ bản và tác động của ENSO đến hạn hán, mưa lớn ở Việt Nam và khả năng dụ báo); Ministry of Science and Technology of Vietnam: Hanoi, Vietnam, 2014.

39. Duc, T.Q. Trend and characteristics of ENSO (In Vietnamese: Xu thế biến động của một số đặc trưng ENSO). VNU J. Sci. Nat. Sci. Technol. 2011, 15, 29-36.

40. Mallakpour, I.; Villarini, G. A simulation study to examine the sensitivity of the Pettitt test to detect abrupt changes in mean. Hydrol. Sci. J. 2016, 61, 245-254. [CrossRef]

41. Nguyen-Le, D.; Matsumoto, J.; Ngo-Duc, T. Onset of the Rainy Seasons in the Eastern Indochina Peninsula. J. Clim. 2015, 28, 5645-5666. [CrossRef]

42. Cuong, D.K.; Dam, D.T.; Duong, D.T.T.; Loi, N.K.; Vo, N.-S.; Kortun, A. Extreme Value Distributions in Hydrological Analysis in the Mekong Delta: A Case Study in Ca Mau and An Giang Provinces, Vietnam. EAI Endorsed Trans. Ind. Networks Intell. Syst. 2019, 6. [CrossRef]

43. Goswami, B.N.; Xavier, P.K. ENSO control on the south Asian monsoon through the length of the rainy season. Geophys. Res. Lett. 2005, 32. [CrossRef]

44. Amekudzi, K.L.; Yamba, I.E.; Preko, K.; Asare, O.E.; Aryee, J.; Baidu, M.; Codjoe, N.A.S. Variabilities in Rainfall Onset, Cessation and Length of Rainy Season for the Various Agro-Ecological Zones of Ghana. Climate 2015, 3, 416-434. [CrossRef] 
45. Vinh, D.H. Analysis of Water Demand and Investigation on Fresh-Water Resources in the Coastal Provinces of the Vietnamese Mekong Delta (In Vietnamese: Phân tích nhu cầu dùng nước và điều tra, đánh giá thực trạng các nguồn nước đến các tỉnh ven biển ĐBSCL); HCMC Institute of Resources Geography, Vietnam Academy of Science and Technology: Ho Chi Minh, Vietnam, 2019.

46. Central Population and Housing Census Steering Committee. General Investigation on Population and Housing-Operations and Results (In Vietnamese: Tổng điều tra dân số và nhà ở thời điểm 0 giờ ngày 1 tháng 4 năm 2019_Tổ chúc thực hiện và kêt quả sơ bộ); Statistical Publishing House: Hanoi, Vietnam, 2019.

47. World Bank Group. Vietnam: Toward a Safe, Clean, and Resilient Water System; World Bank Group: Washington, DC, USA, 2019.

48. Ministry of Construction. Planning on Water Supply in the Vietnamese Mekong Delta up to 2030, and the Vision to 2050 (In Vietnamese: Quy hoạch cấp nước vùng Đồng Bằng sông Cửu Long đến năm 2030, tầm nhìn đến năm 2050); Ministry of Construction: Hanoi, Vietnam, 2016.

49. Campisano, A.; Modica, C. Optimal sizing of storage tanks for domestic rainwater harvesting in Sicily. Resour. Conserv. Recycl. 2012, 63, 9-16. [CrossRef]

50. Campisano, A.; Butler, D.; Ward, S.; Burns, M.J.; Friedler, E.; DeBusk, K.; Fisher-Jeffes, L.N.; Ghisi, E.; Rahman, A.; Furumai, H.; et al. Urban rainwater harvesting systems: Research, implementation and future perspectives. Water Res. 2017, 115, 195-209. [CrossRef]

51. Gires, A.; Gouvello, B. Consequences to water suppliers of collecting rainwater on housing estates. Water Sci. Technol. 2009, 60, 543-553. [CrossRef]

(C) 2020 by the authors. Licensee MDPI, Basel, Switzerland. This article is an open access article distributed under the terms and conditions of the Creative Commons Attribution (CC BY) license (http://creativecommons.org/licenses/by/4.0/). 